\title{
Paraventricular Thalamus Controls Behavior during Motivational Conflict
}

\author{
Eun A. Choi, ${ }^{\star}$ PPhilip Jean-Richard-dit-Bressel, ${ }^{*}$ Colin W.G. Clifford, and $\mathbb{\complement}$ Gavan P. McNally \\ School of Psychology, University of New South Wales Sydney, Sydney 2052, Australia
}

Decision-making often involves motivational conflict because of the competing demands of approach and avoidance for a common resource: behavior. This conflict must be resolved as a necessary precursor for adaptive behavior. Here we show a role for the paraventricular thalamus (PVT) in behavioral control during motivational conflict. We used Pavlovian counterconditioning in male rats to establish a conditioned stimulus (CS) as a signal for reward (or danger) and then transformed the same CS into a signal for danger (or reward). After such training, the CS controls conflicting appetitive and aversive behaviors. To assess PVT involvement in conflict, we injected an adeno-associated virus (AAV) expressing the genetically encoded $\mathrm{Ca}^{2+}$ indicator GCaMP and used fiber photometry to record population PVT Ca ${ }^{2+}$ signals. We show distinct profiles of responsivity across the anterior-posterior axis of PVT during conflict, including an ordinal relationship between posterior PVT CS responses and behavior strength. To study the causal role of PVT in behavioral control during conflict, we injected AAV expressing the inhibitory hM4Di DREADD and determined the effects of chemogenetic PVT inhibition on behavior. We show that chemogenetic inhibition across the anterior-posterior axis of the PVT, but not anterior or posterior PVT alone, disrupts arbitration between appetitive and aversive behaviors when they are in conflict but has no effect when these behaviors are assessed in isolation. Together, our findings identify PVT as central to behavioral control during motivational conflict.

Key words: conflict; motivation; paraventricular thalamus; reward

\section{Significance Statement}

Animals, including humans, approach attractive stimuli and avoid aversive ones. However, they frequently face conflict when the demands of approach and avoidance are incompatible. Resolution of this conflict is fundamental to adaptive behavior. Here we show a role for the paraventricular thalamus, a nucleus of the dorsal midline thalamus, in the arbitration of appetitive and aversive behavior during motivational conflict.

\section{Introduction}

Responding to stimuli or choosing between actions often involves motivational conflict. Being forced to choose between two desired alternatives, choosing something with positive and negative consequences, or choosing between two equally, undesirable alternatives are common. These decisions generate motivational conflict because of the competing demands between approach and avoidance for a common resource: behavior (Miller, 1944,

\footnotetext{
Received Sept. 24, 2018; revised March 28, 2019; accepted April 6, 2019.

Author contributions: E.A.C. and G.P.M. designed research; E.A.C. performed research; E.A.C., P.J.-R.-d.-B., and C.W.G.C. analyzed data; E.A.C. and G.P.M. wrote the paper.

This work was supported by Australia Research Council (DP160100004) Grant to G.P.M. and by a UNSW Postgraduate Award to E.A.C., and by the UNSW Major Research Equipment and Infrastructure Initiative and UNSW School of Psychology.

The authors declare no competing financial interests.

*E.A.C. and P.J.-R.-d.-B. contributed equally to this work.

Correspondence should be addressed to Gavan P. McNally at g.mcnally@unsw.edu.au.

https://doi.org/10.1523/JNEUROSCI.2480-18.2019

Copyright $\odot 2019$ the authors
}

1959; Gray and McNaughton, 2000). This conflict must be resolved as a necessary precursor for adaptive behavior.

The paraventricular thalamus (PVT) may be especially important for behavioral control during conflict. PVT, located in dorsal midline thalamus, contains $12 \sim 20 \mu \mathrm{m}$ aspiny glutamatergic neurons that receive major inputs from prelimbic cortex, hypothalamus, and brainstem and project to infralimbic cortex, nucleus accumbens, bed nucleus of the stria terminalis, and central amygdala (Li and Kirouac, 2008, 2012; Kirouac, 2015; Vertes et al., 2015; Dong et al., 2017). PVT has been implicated in functions including arousal (Colavito et al., 2015), stress (Bhatnagar et al., 2003; Beas et al., 2018), fear (Do-Monte et al., 2015; Penzo et al., 2015), appetitive learning (Otis et al., 2017), incentive salience (Haight and Flagel, 2014), relapse to drug seeking (Hamlin et al., 2009), and feeding (Ong et al., 2017). Recent work suggests that PVT is especially critical during motivational conflict (Li et al., 2014; Choi and McNally, 2017; Zhu et al., 2018). Studies identifying a role for PVT in fear show strong effects of PVT manipulations on reward- and fear-related behavior when these 
are assessed against the background of the other, but less so when assessed in isolation (Li et al., 2014; Choi and McNally, 2017). For example, we reported that chemogenetic silencing of PVT altered expression of defensive and reward-seeking behaviors when these were assessed together but not when they were assessed independently (Choi and McNally, 2017).

However, many questions about this role for PVT in conflict remain unanswered. Notably, few experiments have examined PVT function during tasks that directly assess conflict. Instead, most evidence is derived from preparations where conflict was incidental to other task demands. So, when PVT controls behavior under conflict is poorly understood. Second, PVT can be divided into anterior (aPVT) and posterior (pPVT) portions. PVT neurons are recruited by appetitive or aversive events and their predictors (Zhu et al., 2018) but whether there are differences in activity across aPVT and pPVT is unknown. aPVT has stronger projections to dorsomedial accumbens shell and ventral subiculum whereas PPVT has stronger projections to ventromedial accumbens shell and extended central amygdala (Li and Kirouac, 2012; Colavito et al., 2015; Kirouac, 2015; Vertes et al., 2015; Dong et al., 2017). The functional relevance of these differences in connectivity remain poorly understood (Barson et al., 2015; Kirouac, 2015; Cheng et al., 2018) and whether a role for PVT in conflict depends on aPVT, pPVT, or both is unknown.

Here we studied motivational conflict using Pavlovian counterconditioning (Dickinson and Pearce, 1977; Lovibond and Dickinson, 1982; Nasser and McNally, 2012, 2013; Holmes and Westbrook, 2014). In counterconditioning, a conditioned stimulus (CS) from one motivational class is transformed into a CS of a contrasting motivational class (e.g., signal for reward is transformed into a signal for danger). After counterconditioning, the CS has mixed motivational value, controlling both appetitive and aversive behaviors. We injected an adeno-associated virus (AAV) expressing the genetically encoded $\mathrm{Ca}^{2+}$ indicator GCaMP and used fiber photometry to record population PVT $\mathrm{Ca}^{2+}$ signals during counterconditioning. Next, we injected AAV expressing the inhibitory hM4Di DREADD and determined the effects of chemogenetic inhibition on counterconditioned behavior. Finally, to assess specificity of this role to conflict, we injected PVT with AAV expressing the inhibitory hM4Di DREADD and assessed effects on appetitive and aversive behavior in the absence of conflict. Our findings show robust recruitment of PVT during the learning and expression of motivational conflict and that both aPVT and pPVT, but not either alone, are necessary for behavioral control during conflict.

\section{Materials and Methods}

\section{Subjects}

Subjects were 152 adult male Sprague-Dawley rats (280-350 g) obtained from the Animal Resources Centre and adult male Long-Evans (350$420 \mathrm{~g}$ ) supplied by the University of New South Wales (UNSW). Animals were housed in groups of four in ventilated racks and the room was temperature-controlled with a $12 \mathrm{~h}$ light/dark cycle (lights on at 07:00). Experiments were conducted during the light cycle. Food and water were available ad libitum until $3 \mathrm{~d}$ before the experiment when animals were maintained on $2 \mathrm{~h}$ access to water per day until the end of experiments. The UNSW Animal Care and Ethics Committee approved all procedures.

\section{Apparatus}

Behavioral procedures were conducted in standard operant chambers with grid floors connected to a scrambled shock generator $[24 \mathrm{~cm}$ (length) $\times 30 \mathrm{~cm}$ (width) $\times 21 \mathrm{~cm}$ (height); Med Associates]. A $3 \mathrm{~W}$ house light was mounted on the top of the right wall opposite to the left wall where a recessed magazine $(5 \times 5 \mathrm{~cm})$ was located. The subjects were trained and tested in standard operant chambers (Med Associates), en- closed in sound- and light-attenuating cabinets equipped with fans providing constant ventilation and low-level background noise. For counterconditioning experiments, these chambers were divided into two sets of four, each set had distinct visual, tactile, and olfactory properties (e.g., shock context: a houselight on, grid floor, and peppermint odor; sucrose context: a houselight off, Perspex floor, and rose essence odor). Each chamber contained bedding material in a tray below the floor. Syringe pumps were located above each chamber and were connected to the magazine via polyethylene tubing. A camera was mounted on the back wall of each cabinet to record the behavior of each subject in each chamber. The camera was connected to a monitor and DVD recorder in the room. An infrared light source $(940 \mathrm{~nm})$ illuminated each chamber. All stimulus presentations were controlled by MedPC software (Med Associates).

Locomotor activity was assessed in Plexiglas chambers (Med Associates) $[43.2 \mathrm{~cm}($ width $) \times 43.2 \mathrm{~cm}$ (length) $\times 30.5 \mathrm{~cm}$ (height) $]$. Three 16 beam infrared arrays, located on both the $x$ - and $y$-axes, tracked movement of animals.

\section{Viral vectors}

AAV5-CaMKII $\alpha$-GCaMP6f-WPRE-SV40 $\left(4.25 \times 10^{13} \mathrm{vp} / \mathrm{ml}\right)$ was obtained from Penn Vector Core (University of Pennsylvania, Philadelphia, $\mathrm{PA}$ ). AAV5 vector encoding hM4Di (AAV5-CaMKII $\alpha$-HA-hM4DiIRES-mCitrine, $2 \times 10^{12} \mathrm{vp} / \mathrm{ml}$ ) or eYFP (AAV5-CaMKII $\alpha$ - eYFP, $4 \times$ $10^{12} \mathrm{vp} / \mathrm{ml}$ ) were obtained UNC Vector Core (University of North Carolina, Chapel Hill, NC; Armbruster et al., 2007). Rats were injected intraperitoneally with clozapine- $\mathrm{N}$-oxide (CNO; National Institute of Mental Health Chemical Synthesis and Drug Supply Program, RTI International, NIMH Code C- $929 ; 10 \mathrm{mg} / \mathrm{ml}, 5 \%$ DMSO, $2 \mathrm{ml} / \mathrm{kg}$ ) or vehicle (5\% DMSO, 2 ml/kg; Mahler et al., 2014; Smith et al., 2016; Choi and McNally, 2017) $45 \mathrm{~min}$ before the test. CNO dose was chosen based on our past research showing that it yields a minimum $40-50 \%$ reduction in c-Fos expression among DREADD-expressing PVT neurons (Choi and McNally, 2017) without having nonspecific effects on behavior (see Fig. $4 E, F$ ).

\section{Surgery}

Rats received intracranial stereotaxic surgery under ketamine (Ketamil, $100 \mathrm{mg} / \mathrm{ml}$; Ilium)-xylazine (Xylazil, $20 \mathrm{mg} / \mathrm{M}$; Ilium) anesthesia after subcutaneous injection of $0.1 \mathrm{ml}$ of atropine sulfate (Atrosite, $0.65 \mathrm{mg} /$ $\mathrm{ml}$; Ilium). Once anesthetized, the heads were shaved, and rats were placed in a stereotaxic apparatus (Model 942, Kopf Instruments). $0.1 \mathrm{ml}$ of $0.5 \%$ bupivacaine was injected at the incision site and $0.05 \mathrm{ml}$ of carprofen (Rimadyl, $50 \mathrm{mg} / \mathrm{m}$; Zoetis) injected subcutaneously. The skull was exposed, and a craniotomy made using a hand drill above the target PVT region. For anterior PVT the stereotaxic coordinates were as follows: $-1.8 \mathrm{AP}, 0.1 \mathrm{ML},-6.0 \mathrm{DV}$. For posterior PVT the stereotaxic coordinates were as follows: $-3.4 \mathrm{AP}, 0.1 \mathrm{ML},-6.0 \mathrm{DV}$. For combined anterior and posterior PVT the stereotaxic coordinates were as follows: -2.6 AP, 0.1 ML, -6.0 DV, and -3.6 AP, 0.1 ML, -6.1 DV. All stereotaxic coordinates are in millimeters from bregma (Paxinos and Watson, 2007). All AAV infusions were made over a $3-5 \mathrm{~min}$ period at a rate of 0.1 $\mu \mathrm{l} / \mathrm{min}(0.5 \mu \mathrm{l}$ for fiber photometry experiments; $0.3 \mu \mathrm{l}$ each spot for DREADD experiments; UMP3 with SYS4 Micro-controller, World Precision Instruments) and the syringe ( $1 \mu \mathrm{l}, 23$-gauge conical tipped microinfusion syringe, SEG) remained in place for 5-7 min to permit diffusion of the injected vectors. For fiber photometry rats received implantations of $400 \mu \mathrm{m}$ optic fibers into anterior PVT (1.8 AP, 0.1 ML, $-5.5 \mathrm{DV})$ or posterior PVT (-3.4 AP, 0.1 ML, $-5.7 \mathrm{DV})$. All stereotaxic coordinates are in millimeters from bregma (Paxinos and Watson, 2007). Immediately after surgery, rats were subcutaneously injected with $0.3 \mathrm{ml}$ of procaine penicillin (Benicillin, $300 \mathrm{mg} / \mathrm{ml}$; Illium) and $0.3 \mathrm{ml}$ of cephazolin sodium (Cephazolin, $100 \mathrm{mg} / \mathrm{ml}$; Hospira). Daily postoperative and recovery procedures were conducted over $7 \mathrm{~d}$.

\section{Behavioral procedures}

Experiment 1: fiber photometry of PVT during appetitive-to-aversive counterconditioning. On Days 1 and 2, rats $(n=16)$ were exposed to the two contexts for $20 \mathrm{~min}$ each. There was a $90 \mathrm{~min}$ interval between exposures on the same day. During exposure to the to-be aversive context there 
were no scheduled events. During exposure to the to-be appetitive context, rats received unsignaled $20 \times 0.15 \mathrm{ml}$ presentations of an $8 \%$ sucrose solution on variable time 60 s schedule. On Days 3-9, rats received daily Pavlovian appetitive conditioning in the appetitive context. This conditioning consisted of eight $85 \mathrm{~dB}[\mathrm{~A}] 1800 \mathrm{~Hz}$ tone, $30 \mathrm{~s}$ tone CSsucrose unconditioned stimulus (US; $0.15 \mathrm{ml}$ ) pairings with an intertrial interval of $3 \mathrm{~min}$. The US was delivered randomly at 5, 10, 15, 20, or $25 \mathrm{~s}$ after CS onset. On Day 10, rats received a single session of Pavlovian fear conditioning in the aversive context that consisted of four tone CS- 0.4 $\mathrm{mA} 0.5 \mathrm{~s}$ shock (US) pairings. The CS was the same as that used during appetitive conditioning. Fear conditioning commenced after a $6 \mathrm{~min}$ baseline period. The US was delivered randomly at $5,10,20$, or $25 \mathrm{~s}$ after $\mathrm{CS}$ onset with a fixed $3 \mathrm{~min}$ intertrial interval. Rats remained undisturbed in their home cages on Days 11 and 12. On Days 13 and 14 rats were tested. During these tests, there were eight $30 \mathrm{~s}$ presentations of the CS with a fixed intertrial interval of $2 \mathrm{~min}$. CS presentations began $2 \mathrm{~min}$ after placement in the context. One of these tests was conducted in the appetitive context whereas the other was conducted in the aversive context. The order of these tests was counterbalanced within animals.

Experiment 2: fiber photometry of PVT during aversive-to-appetitive counterconditioning. On Days 1 and 2, rats $(n=24)$ were exposed to the two contexts for $20 \mathrm{~min}$ each. The procedure for these exposures was identical to that described above. On Day 3 , rats received a single session of Pavlovian fear conditioning in the aversive context. This was identical to fear conditioning described above. On Days 4-10, rats received daily Pavlovian appetitive conditioning in the appetitive context and this was also identical to that described above. Rats remained undisturbed in their home cages on Days 11 and 12. On Days 13 and 14 rats were tested. The procedures for these tests were identical to those described for Experiment 1 and the order of tests was counterbalanced within animals.

Experiments 3a-3c: chemogenetic inhibition of PVT (Experiment $3 a$ ), aPVT (Experiment 3b), or pPVT (Experiment 3c) on appetitive-to-aversive counterconditioning. On Days 1 and 2 , rats ( $n=16$ per experiment) were exposed to the two contexts for $20 \mathrm{~min}$ each. The procedures for these exposures were identical to that described above. On Days 3-9, rats received daily Pavlovian appetitive conditioning in the appetitive context. The procedure for this was identical to that described above. On Day 10, rats received a single session of Pavlovian fear conditioning in the aversive context. The procedure was identical to that described above. Rats remained undisturbed in their home cages on Days 11 and 12. On Days 13 and 14 rats were tested for CS responses in the appetitive and aversive contexts. The procedures for these tests were identical to that described for Experiment 1. The order of these tests was counterbalanced within animals. Rats received CNO injection 45 min before these tests.

Experiment 4: chemogenetic inhibition of PVT on aversive-to-appetitive counterconditioning. On Days 1 and 2, rats $(n=16)$ were exposed to the two contexts for $20 \mathrm{~min}$ each. The procedures for these exposures were identical to that described above. On Day 3, rats received a single session of Pavlovian fear conditioning in the aversive context. This was identical to that described above. On Days $4-7$, rats received daily Pavlovian appetitive conditioning in the appetitive context and this was identical to that described above. On Days 8 and 9, rats were tested. The procedures for these tests were identical to that described above. The order of these tests was counterbalanced within animals. Rats received CNO injection 45 min before these tests.

Experiments 5a-5d: chemogenetic inhibition of PVT during appetitive (Experiments $5 a$ and $5 b$ ) or aversive (Experiment $5 c$ ) memory retrieval and on locomotor activity. In Experiment $5 \mathrm{a}(n=16)$, on Days $1-7$, rats received daily appetitive conditioning in a manner identical to the appetitive conditioning used in the counterconditioning experiments. Rats remained undisturbed in their home cages on Days 8 and 9 and were tested on Day 10 via eight 30 s CS presentations with a 3 min intertrial interval. Rats received CNO injections $45 \mathrm{~min}$ before test.

In Experiment 5b, on Days $1-4$, rats $(n=16$ from Experiment 4$)$ received 4 daily $30 \mathrm{~min}$ appetitive conditioning sessions. These consisted of 8 clicker [85db[A], $10 \mathrm{~Hz}(\mathrm{CS})]$-sugar pellet [45 mg, Dustless precision pellet sugar, Bio-Serv (US)] pairings. The US was delivered randomly $5,10,15,20$, or $25 \mathrm{~s}$ after CS onset. The intertrial interval was 3 min. On Day 5, rats were tested via eight 30 s CS presentations with a 3 min intertrial interval. Rats received CNO injections 45 min before this test.

In Experiment $5 c(n=16)$, rats received a single session of fear conditioning on Day 1 . This consisted of four tone (CS)-shock (US) pairings in a manner identical to the fear conditioning used in the counterconditioning experiments. Rats remained in their home case on Days 2 and 3. They were tested on Day 4. This involved a $2 \mathrm{~min}$ pre-CS before eight $30 \mathrm{~s}$ CS presentations with a 3 min intertrial interval. Rats received CNO injections $45 \mathrm{~min}$ before this test.

In Experiment 5d, on Days 1 and 2, rats ( $n=16$ from Experiment 5c) were habituated to the chambers for $30 \mathrm{~min}$. On Days 3 and 5 they were tested for $30 \mathrm{~min}$. One of these tests was preceded by injection of $\mathrm{CNO}$ whereas the other was preceded by injection of vehicle. Injections were counterbalanced and occurred 45 min before test.

\section{Fiber photometry}

Recordings were performed using Fiber Photometry Systems from Doric Lenses and Tucker Davis Technologies (RZ5P, Synapse). Two excitation wavelengths, $465 \mathrm{~nm}\left(\mathrm{Ca}^{2+}\right.$-dependent signal) and $405 \mathrm{~nm}$ (isobestic control signal) emitted from Doric LEDs, controlled via dual channel programmable LED drivers, were channeled into $400 \mu \mathrm{m}$ pre-bleached patch cables via a Doric Dual Fluorescence Mini Cube. Light intensity at the tip of the patch was maintained at $10-40 \mu \mathrm{W}$ across sessions. GCaMP6 and isobestic fluorescence wavelengths were measured using femtowatt photoreceivers (Newport, 2151). Synapse software controlled and modulated excitation lights ( $465 \mathrm{~nm}: 209 \mathrm{~Hz}, 405 \mathrm{~nm}: 331 \mathrm{~Hz}$ ), as well as demodulated and low-pass filtered $(3 \mathrm{~Hz})$ transduced fluorescence signals in real-time via the RZ5P. Synapse/RZ5P also received Med-PC signals to record behavioral events and experimenter-controlled stimuli in real time.

\section{Immunohistochemistry}

Rats were anesthetized within 2 weeks of the end of behavioral training and fixed brains were extracted, postfixed, and cryoprotected in $20 \%$ sucrose $(24-48 \mathrm{~h})$. Brains were sectioned and stored in $0.1 \%$ sodium azide in $0.1 \mathrm{M}$ PBS, pH 7.2. An eGFP antibody was used to detect GCaMP, DREADD, or eYFP-expressing cells. Sections were washed [0.1 M PB, pH7.4, 50\% ethanol, 50\% ethanol with 3\% hydrogen peroxidase, and then $5 \%$ normal horse serum (NHS) in PB for $30 \mathrm{~min}$ each], then incubated for 24-48 $\mathrm{h}$ in chicken antiserum against eGFP (1:2000; ThermoFisher Scientific, catalog\# A10262; RRID:AB_2534023) diluted in a PB containing $2 \%$ NHS and $0.2 \%$ Triton $\mathrm{X}-10$ in $0.1 \%$ sodium azide at room temperature. After washing in $\mathrm{PB}$, sections were incubated in biotinylated donkey anti-chicken (1:2000; Jackson ImmunoResearch, catalog\# 703-065-155; RRID:AB_2313596), $24 \mathrm{~h}$ at room temperature, diluted in a PB solution blocking buffer ( $2 \%$ NHS and $0.2 \%$ Triton X-10 in PB). The sections were washed then incubated in avidin-biotinylated horseradish peroxidase complex (ABC solution; Vector Elite kit: $6 \mu \mathrm{l} / \mathrm{ml}$ avidin and $6 \mu \mathrm{l} / \mathrm{ml}$ biotin; Vector Laboratories), diluted in PB containing $0.2 \%$ Triton $\mathrm{X}-10$ for $2 \mathrm{~h}$ at room temperature. Then, the sections were washed twice in PB and once in $0.1 \mathrm{M}$ acetate buffer, $\mathrm{pH}$ 6.0, and incubated (15 min) in a diaminobenzidine (DAB) solution containing $0.1 \%$ 3,3-diaminobenzidine, $0.8 \% \mathrm{D}$-glucose and $0.016 \%$ ammonium chloride. Immunoreactivity was catalyzed by the addition of $0.2 \mu \mathrm{l} / \mathrm{ml}$ glucose oxidase ( $24 \mathrm{mg} / \mathrm{ml}, 307 \mathrm{U} / \mathrm{mg}$; Sigma-Aldrich). GCaMP expression in PVT was also assessed via native GCaMP fluorescence; sections washed for $30 \mathrm{~min}$ in $\mathrm{PB}$, mounted and coverslipped (Permfluor, ThermoFisher Scientific).

For c-Fos and eYFP immunohistochemistry, rats were anesthetized $2 \mathrm{~h}$ and $45 \mathrm{~min}$ after injection of $20 \mathrm{mg} / \mathrm{kg}$ CNO. Two-color peroxidase immunohistochemistry was used to detect c-Fos and eYFP immunoreactivity. Sections were washed in $0.1 \mathrm{M} \mathrm{PB}, 50 \%$ ethanol, $50 \%$ ethanol with $3 \%$ hydrogen peroxidase, and then $5 \%$ NHS in PB as mentioned above and allowed for $48 \mathrm{~h}$ to incubate in rabbit anti-c-Fos (1:2000; Santa Cruz Biotechnology, catalog \#sc-52; RRID:AB_2106783) and chicken antiserum against eGFP (1:2000; ThermoFisher Scientific, catalog \#A10262; RRID:AB_2534023) diluted in a PB solution blocking buffer in $0.1 \%$ sodium azide for $48 \mathrm{~h}$ at room temperature. After washing in PB, they were incubated in biotinylated donkey anti-rabbit (1:2000; Jackson 
ImmunoResearch, catalog \# 711-065-152; RRID:AB_2340593), $24 \mathrm{~h}$ at room temperature, diluted in $2 \%$ NHS and $0.2 \%$ Triton X-10 in PB for c-Fos IR. The sections were then washed in $\mathrm{PB}$ and incubated in $\mathrm{ABC}$ solution. Then, the sections were washed in $\mathrm{PB}$ and once in $0.1 \mathrm{M}$ acetate buffer, $\mathrm{pH}$ 6.0, and then incubated (15 min) in a DAB solution containing Nickel (II) sulfate hexahydrate (Sigma-Aldrich, N4882) for black color. Immunoreactivity was catalyzed by $0.2 \mu \mathrm{l} / \mathrm{ml}$ glucose oxidase, stopped the reaction in acetate buffer and washed in PB three times. Then the sections were incubated in biotinylated donkey anti-chicken (1:2000; Jackson ImmunoResearch, catalog \#703-035-155; RRID:AB_10015283), $24 \mathrm{~h}$ at room temperature, diluted in $2 \%$ NHS and $0.2 \%$ Triton X-10 in $\mathrm{PB}$ for eYFP IR. After washing in PB and once in acetate buffer it was incubated in DAB solution without Nickel (II) sulfate hexahydrate for brown color. The reaction was catalyzed by adding $0.2 \mu \mathrm{l} / \mathrm{ml}$ glucose oxidase and stopped in acetate buffer. Then brain sections were then washed in PB and then mounted and coverslipped with Entellan.

\section{Experimental design and statistical analyses}

The criteria for inclusion in final analyses were correct AAV and fiber placements in PVT as determined after histology, so animals were excluded if either AAV or fiber optic cannulae were misplaced. To measure fear behaviors, rats were scored every $2 \mathrm{~s}$ as either freezing (a crouching immobile posture with no movement other than required for respiration; Blanchard and Blanchard, 1971; Fanselow and Bolles, 1979) or not freezing. The number of observations scored as freezing were summed and converted to a percentage. The numbers of magazine entries during the CS and a $30 \mathrm{~s}$ pre-CS period were recorded via MedPC. Behavioral data were analyzed in the Psy Statistical Package (Bird, 2004) using between-subject (aPVT vs pPVT), within-subject (sessions or trials), as well as interaction contrasts (Harris, 1994).

For fiber photometry, the primary dependent variable was $\mathrm{Ca}^{2+}$ transients around CS and US presentations during appetitive training (Sessions 1, 3, 5, and 7), US presentations during aversive conditioning, and CS presentations on test (appetitive and aversive contexts). These data were analyzed using custom MATLAB scripts. Specifically, $\mathrm{Ca}^{2+}$ and isobestic signals during recording sessions were extracted and downsampled (15.89 samples/s); signals around logged disconnections were removed before further signal processing. The isobestic signal was regressed onto the $\mathrm{Ca}^{2+}$-dependent signal to create a fitted isobestic signal and a $\Delta F / F$ was calculated via: $\left(\mathrm{Ca}^{2+}\right.$-dependent signal - fitted isobestic)/fitted isobestic. This produces a motion-artifact-corrected $\mathrm{Ca}^{2+}$ signal with a mean of $\sim 0$. Signal-to-noise was further boosted via filtering after contributions of low and high-frequency components were determined via fast Fourier transform; $\Delta \mathrm{F} / \mathrm{F}$ signal was convolved over $90 \mathrm{~s}$ (high-pass filtered) and then low-pass filtered at $1 \mathrm{~Hz}$.

$\Delta \mathrm{F} / \mathrm{F}$ within a time window around events was compiled and averaged for each subject. To determine any change in $\mathrm{Ca}^{2+}$ transients during this window, a bootstrapping confidence interval (CI) procedure $(99 \% \mathrm{CI}$, 1000 iterations) was used (Bland and Altman, 2015). A new "mean" $\Delta F / F$ was generated by randomly resampling from subject mean $\Delta \mathrm{F} / \mathrm{F}$ with replacement for the same number of samples. So, $n$ for all statistical analyses of photometry data were the number of subjects in each group. This process was repeated 1000 times to create a nonparametric distribution of population mean estimates for each time point within the window. A statistically significant increase $(>0 \%)$ in $\mathrm{Ca}^{2+}$ transients was defined as those where the lower bound of the $99 \%$ CI was $>0$ (Bird, 2004; Bland and Altman, 2015). To analyze differences in CS-elicited PVT activity between appetitive and aversive tests, an area under the curve (AUC) of $\% \Delta \mathrm{F} / \mathrm{F}$ was obtained using the trapezoidal method for $0.5-1.5 \mathrm{~s}$ after CS onset, and compared using within-subject contrasts.

To examine the relationship between CS-elicited PVT activity and conditioned responding across training, correlational analyses were performed. To overcome between-subject differences in behavior and photometry signals, CS-elicited activity (0.5-1.5 s AUC) and accompanying conditioned responding were normalized per subject across sessions [Experiment 1: appetitive conditioning Sessions 1, 3, 5, 7 (session average)] or trials (Experiment 2: aversive conditioning Trials 1-4). Fisher r-to- $z$ transformation was used to compare predictions of behavioral strength between aPVT and pPVT.
To verify hM4Di inhibition of PVT, we assessed expression of the immediate-early gene c-Fos in PVT. c-Fos-IR and eYFP-IR were imaged at $20 \times$ using a transmitted light microscope (Olympus BX51) and counted using Photoshop (Adobe). Three sections from each brain were counted and the sections were located $-2.52,-3.0$, and $-3.60 \mathrm{~mm}$ from bregma. These data were analyzed using between-subjects ANOVA.

\section{Results}

\section{Experiment 1: fiber photometry of PVT during} appetitive-to-aversive counterconditioning

First, we used fiber photometry to examine $\mathrm{Ca}^{2+}$ signals in aPVT or pPVT during motivational conflict generated by transforming a reward signal into a danger signal. We used AAV to express GCaMP6 in aPVT or pPVT in separate animals and implanted fiber optic cannulae into these regions. Rats then received appetitive-toaversive counterconditioning that involved $7 \mathrm{~d}$ of Pavlovian appetitive conditioning where an auditory CS was paired with sucrose delivery. Next, they received $1 \mathrm{~d}$ of Pavlovian aversive conditioning where the CS was paired with shock. These two stages of training were conducted in different contexts to ensure adequate expression of both behaviors. Rats were then tested for appetitive and aversive responses to the CS in the two contexts. At the end of this training, the CS controls conflicting appetitive and aversive behaviors. We recorded $\mathrm{Ca}^{2+}$ signals (to the CS, appetitive US, and aversive US) in aPVT or pPVT on Days 1, 3, 5, and 7 during appetitive conditioning, during fear conditioning, and during tests. The questions of interest were how do $\mathrm{Ca}^{2+}$ signals relate to the CS, appetitive US, aversive US, the emergence of behavior, and do these differ across aPVT and pPVT?

\section{Histology}

Only rats with both GCaMP expression and fiber optic placements in the aPVT or pPVT were included. Six animals were excluded because of incorrect placements, leaving final group sizes of $n=6$ (aPVT) and $n=4$ (pPVT). Figure $1 A$ shows representative images showing native GCaMP expression (green) and DAPI staining (blue) in PVT, example of GCaMP expression in aPVT and pPVT with an optic fiber placement from separate animals, and a complete mapping of the location of fiber tips for each animal included in the analyses. Figure $1 B$ shows representative $\mathrm{Ca}^{2+}$-dependent signals and isobestic control signals in aPVT and pPVT from appetitive (aPVT) and aversive (pPVT) training sessions.

\section{Appetitive conditioning}

In this and remaining experiments, levels of pre-CS magazine entries were low and did not differ significantly between groups (all $p>0.05$ ). During Pavlovian appetitive conditioning (Fig. $1 C)$, rats readily learned to approach the magazine during CS presentations. There was a main effect of day $\left(F_{(1,8)}=36.480, p<\right.$ $0.001)$. There was no difference between aPVT and pPVT groups $\left(F_{(1,8)}=1.774, p=0.220\right)$ and there was no interaction between Group and Day $\left(F_{(1,8)}=2.066, p=0.189\right)$.

Using fiber photometry, we examined PVT $\mathrm{Ca}^{2+}$ signals in the aPVT and pPVT during CS and appetitive US presentations on Days 1, 3, 5 and 7 of conditioning. We used a bootstrapped 99\% CI procedure (Bland and Altman, 2015) to estimate population mean $\% \Delta \mathrm{F} / \mathrm{F}$ during the $1 \mathrm{~s}$ prior and $3 \mathrm{~s}$ following $\mathrm{CS}$ and US presentations. A significant increase in $\% \Delta \mathrm{F} / \mathrm{F}$ from 0 to $3 \mathrm{~s}$ after events was determined whenever the lower bound of the $99 \%$ CI was $>0$. These points of statistical significance are shown as colored lines above the $\% \Delta \mathrm{F} / \mathrm{F}$ curve. aPVT showed robust and significant $\mathrm{Ca}^{2+}$ signals to CS presentations but, surprisingly, not 
A
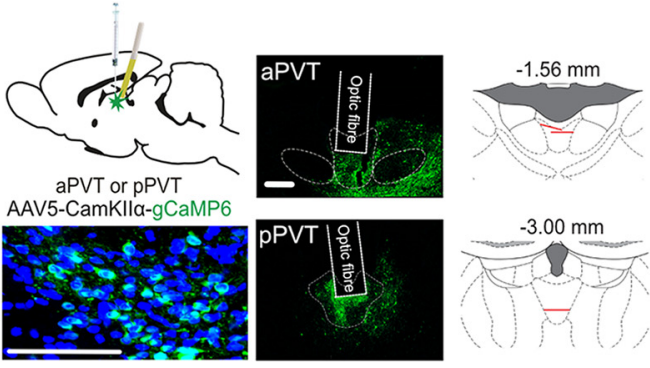

B

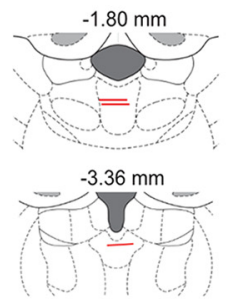

aPVT

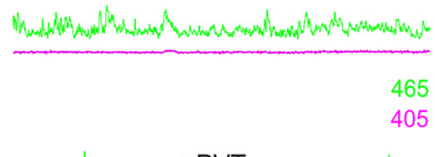

PPVT

$\overline{25 s}$
C

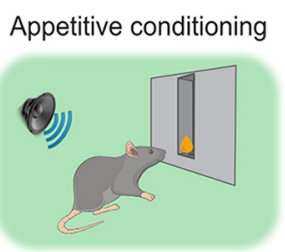

$\mathrm{CS} \rightarrow$ Sucrose
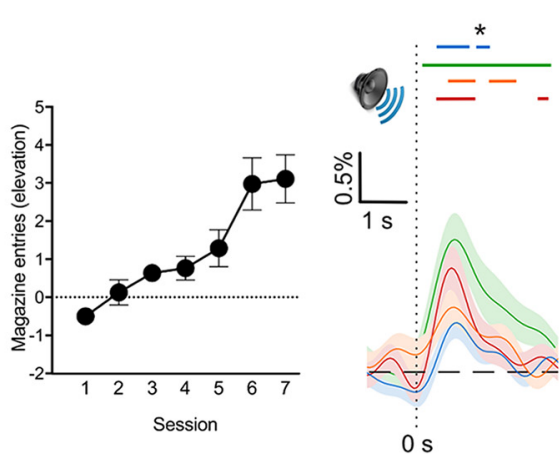

aPVT
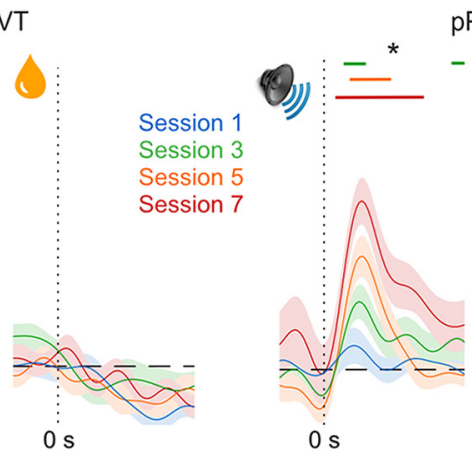

pPVT

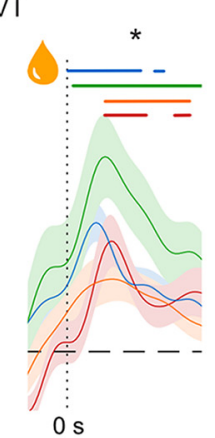

aPVT
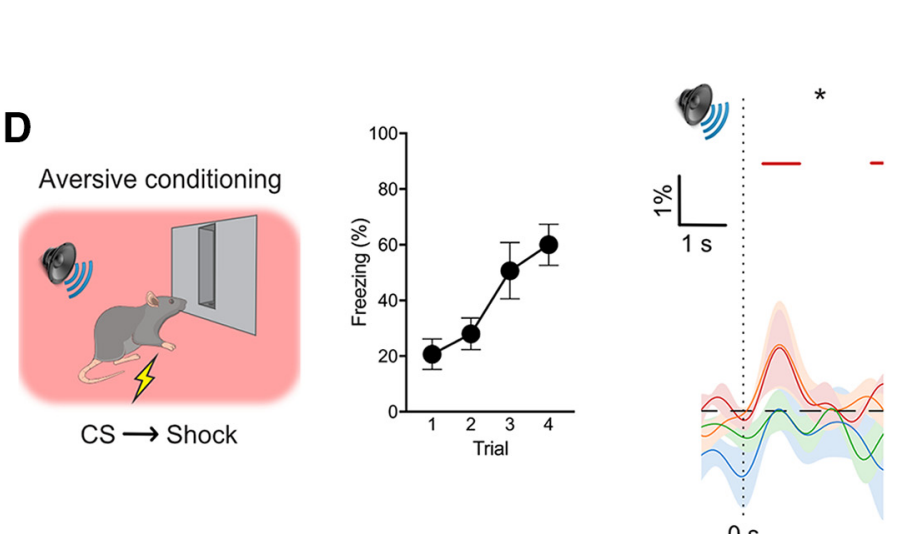

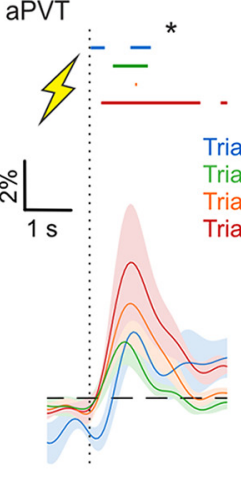

$0 \mathrm{~s}$

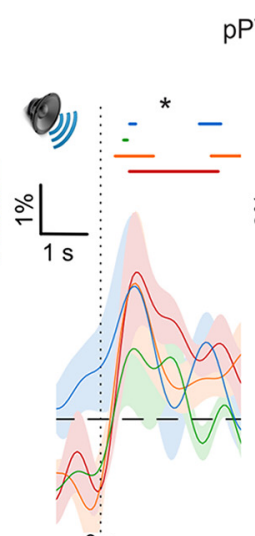

o's

pPVT

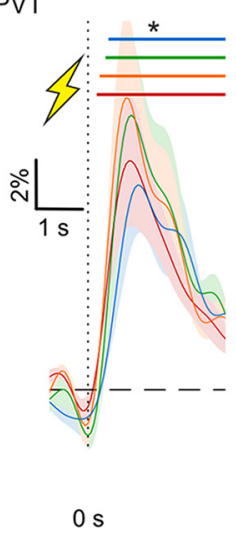

E

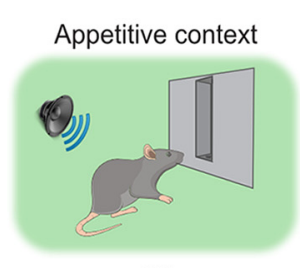

CS

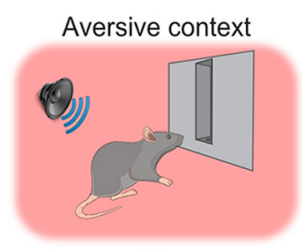

CS
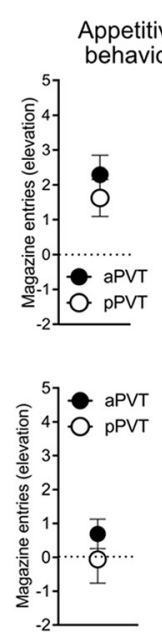
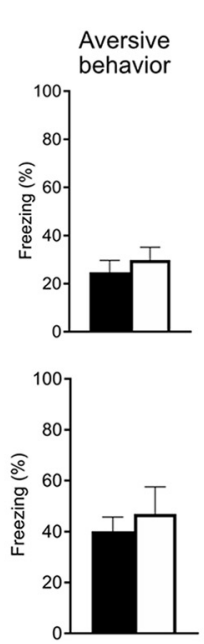

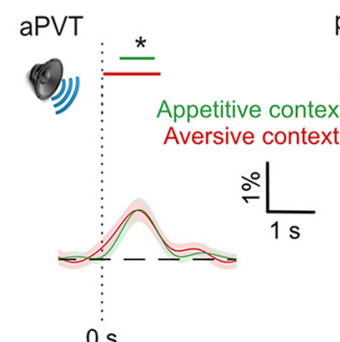

pPVT

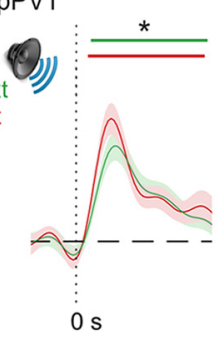

PPVT

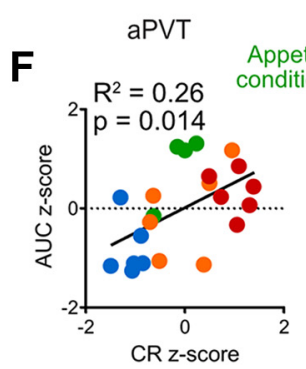

Appetitive

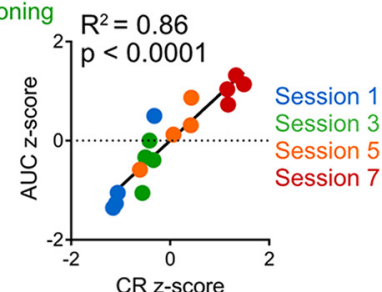

Figure 1. Experiment 1.A, AAV was used to express GCaMP6 in aPVT or pPVT in separate animals and fiber optic cannulae implanted into these regions. Representative images show native GCaMP expression and DAPI staining in PVT (green, native GCaMP; blue, DAPI; scale bar, $100 \mu \mathrm{m}$ ), native GCaMP expression for aPVT and pPVT (scale bar, $500 \mu \mathrm{m}$ ), as well as location of fiber tips for all animals included in the analyses. $\boldsymbol{B}$, Representative demodulated photometry traces from aPVT (during appetitive training) and pPVT (during aversive training). (Figure legend continues.) 
to reward consumption. aPVT signals to CS presentations were variable across days, with no obvious relationship between these and the amount of training (Fig. 1C). In contrast, pPVT showed robust and significant $\mathrm{Ca}^{2+}$ signals to both CS presentations and reward consumption (Fig. 1C). Moreover, there was an ordinal relationship between PVT $\mathrm{Ca}^{2+}$ signals to CS presentations and training days.

To further investigate the relationship between CS transients and behavior, we used correlational analyses (Fig. $1 F$ ). CSelicited PVT activity (AUC 0.5-1.5 s after CS) and accompanying conditioned responding were normalized per subject. CS-elicited aPVT Ca ${ }^{2+}$ signals were a weak but significant predictor of magazine approach behavior $\left(R^{2}=0.26, F_{(1,20)}=7.317, p=0.014\right)$. In contrast, CS-elicited pPVT Ca ${ }^{2+}$ signals were an excellent predictor of magazine approach behavior $\left(R^{2}=0.86, F_{(1,14)}=86.70\right.$, $p<0.0001)$. pPVT Ca ${ }^{2+}$ signals were a significantly better predictor of magazine approach $(z=2.97, p=0.003$, Fisher $r$-to- $z$ transformation) compared with aPVT $\mathrm{Ca}^{2+}$ signals.

\section{Aversive conditioning}

In this and remaining experiments, levels of pre-CS freezing were low and did not differ significantly between groups (all $p>0.05$ ). During Pavlovian aversive conditioning (Fig. 1D), rats readily acquired fear responses to the CS. There was a significant increase in CS-evoked freezing across trials $\left(F_{(1,8)}=35.073, p<0.001\right)$. This fear conditioning was the same across both groups because there was no main effect of $\operatorname{Group}\left(F_{(1,8)}=1.304, p=0.287\right)$ and no Group $\times$ Trial interaction $\left(F_{(1,8)}=0.989, p=0.349\right)$.

Using fiber photometry, we examined PVT $\mathrm{Ca}^{2+}$ signals in the aPVT and pPVT during CS and aversive US presentations across the single day of aversive conditioning (Fig. 1D). There were weak CS-related $\mathrm{Ca}^{2+}$ signals in aPVT that reached significance only toward the end of training and stronger CS-related $\mathrm{Ca}^{2+}$ signals in pPVT that were significant on each trial. There were also robust and significant shock US-related $\mathrm{Ca}^{2+}$ signals in both aPVT and pPVT across most training days (Fig. 1D). So, whereas $\mathrm{PPVT}$ was responsive to both the aversive and appetitive US, aPVT was responsive only to the aversive US.

\section{Test}

Rats were tested twice, once in the aversive context and once in the appetitive context. As expected (Nasser and McNally, 2012, 2013; Holmes and Westbrook, 2014), rats expressed appetitive (i.e., magazine entries) and aversive (i.e., freezing) behavior in both contexts (Fig. 1E). There was some context-dependency in expression of these behaviors, so for appetitive behaviors there

\footnotetext{
$\leftarrow$

(Figure legend continued.) C, Rats received Pavlovian appetitive conditioning and acquired magazine entries during the $C S$. Photometry traces show mean \pm SEM $\% \Delta F / F$ across trials for the $1 \mathrm{~s}$ prior and $3 \mathrm{~s}$ after $C S$ and appetitive US presentations. $D$, Rats received Pavlovian aversive conditioning and acquired fear responses to the CS. Photometry traces show mean \pm SEM $\% \Delta \mathrm{F} / \mathrm{F}$ across trials for the $1 \mathrm{~s}$ prior and $3 \mathrm{~s}$ after $\mathrm{CS}$ and aversive US presentations. $\boldsymbol{E}$, Rats were tested for appetitive and aversive behaviors in their respective training contexts. There was robust expression of appetitive and aversive behaviors. Photometry traces show mean \pm SEM $\% \Delta \mathrm{F} / \mathrm{F}$ across trials for the $1 \mathrm{~s}$ prior and $3 \mathrm{~s}$ after $\mathrm{CS}$ presentations in each context. In each panel, a significant increase in $\% \Delta \mathrm{F} / \mathrm{F}$ was determined whenever the lower bound of the $99 \% \mathrm{Cl}$ was $>0$. These points of statistical significance are shown as colored lines above each $\% \Delta \mathrm{F} / \mathrm{F}$ curve with different colors corresponding to the respective traces from sessions $(\boldsymbol{C})$ or trials $(\boldsymbol{D})$. aPVT, $n=6 ;$ PPVT, $n=4$. F, Scatterplots of subject-normalized CS-elicited PVT activity (AUC $0.5-1.5$ $s$ from (S onset) and associated conditioned responding across initial appetitive conditioning sessions. *Indicates lower bound $99 \% \mathrm{Cl}>0 \% \Delta \mathrm{F} / \mathrm{F}$ (colored lines above traces). aPVT, $n=6$; $\mathrm{pPVT}, n=4$.
}

was a main effect of Context $\left(F_{(1,8)}=9.351, p=0.016\right)$ showing more CS-elicited appetitive behaviors in the appetitive context but there was no main effect of Group $\left(F_{(1,8)}=1.451, p=0.263\right)$ and no Group $\times$ Context interaction $\left(F_{(1,8)}=0.006, p=0.940\right)$. For aversive behaviors, there was a main effect of Context $\left(F_{(1,8)}=\right.$ $5.871, p=0.042)$, showing more CS-elicited freezing in the aversive context, with no main effect of Group $\left(F_{(1,8)}=0.813, p=\right.$ $0.394)$ and no Group $\times$ Context interaction $\left(F_{(1,8)}=0.015, p=\right.$ 0.906). Fiber photometry showed that both aPVT and pPVT exhibited significant CS-evoked $\mathrm{Ca}^{2+}$ signals during tests (Fig. 1E), with no obvious difference in the magnitude of these signals across the appetitive and aversive contexts (AUC; aPVT: $F_{(1,5)}=$ $0.001, p=0.976$, pPVT: $\left.F_{(1,3)}=0.266, p=0.628\right)$.

\section{Experiment 2: fiber photometry of PVT during aversive-to-appetitive counterconditioning}

Next, we used fiber photometry to examine PVT activity during motivational conflict generated by transforming a danger signal into a reward signal. To do this, we reversed the order of behavioral training so that rats first received fear conditioning of a CS and then received appetitive conditioning with the same CS. The questions of interest were how do $\mathrm{Ca}^{2+}$ signals relate to the CS, appetitive US, and aversive US, do these differ across aPVT and pPVT, and were these changes similar to or different to those observed in Experiment 1?

\section{Histology}

Six animals were excluded because of misplacement of either GCaMP expression or fiber optic, leaving final group sizes of $n=$ 10 (aPVT) and $n=8$ (pPVT). Figure $2 A$ shows representative GCaMP expression in aPVT and pPVT (from separate animals as well as location of fiber tips for each animal included in the analyses. Figure $2 B$ shows representative $\mathrm{Ca}^{2+}$-dependent signals and isobestic control signals in aPVT (aversive training) and pPVT (appetitive training) from behavioral training sessions.

\section{Aversive conditioning}

Rats readily acquired fear responses to the CS (Fig. 2C). There was a main effect of trial $\left(F_{(1,16)}=102.202, p<0.001\right)$, but no difference between aPVT and pPVT groups $\left(F_{(1,16)}=0.005, p=\right.$ $0.945)$ or interaction between Group and Trial $\left(F_{(1,16)}=0.157\right.$, $p=0.697$ ). Similar to Experiment 1, during Pavlovian aversive conditioning, aPVT showed significant $\mathrm{Ca}^{2+}$ signals to the CS and footshock US with no obvious relationship between the magnitude of $\mathrm{Ca}^{2+}$ signals and conditioning trials. pPVT showed robust and significant $\mathrm{Ca}^{2+}$ signals to both CS and footshock US. In contrast to aPVT, there was an ordinal relationship between pPVT $\mathrm{Ca}^{2+}$ signals and the number of aversive conditioning trials.

To further investigate the relationship between CS transients and behavior, we used correlational analyses (Fig. $2 F$ ). CSelicited aPVT Ca ${ }^{2+}$ signals failed to predict defensive freezing behavior $\left(R^{2}=0.004, F_{(1,38)}=0.154, p=0.697\right)$. In contrast, CS-elicited pPVT Ca ${ }^{2+}$ signals were an excellent, significant predictor of defensive freezing behavior $\left(R^{2}=0.36, F_{(1,30)}=17.01\right.$, $p=0.0003)$. $\mathrm{pPVT} \mathrm{Ca}^{2+}$ signals were a significantly better predictor of defensive freezing $(z=2.55, p=0.0108$, Fisher $r$-to- $z$ transformation) compared with aPVT $\mathrm{Ca}^{2+}$ signals.

\section{Appetitive conditioning}

During Pavlovian appetitive conditioning (Fig. 2D), rats readily learned to approach the magazine during CS presentations. For CS-elicited magazine entries, there was a main effect of Day 
A

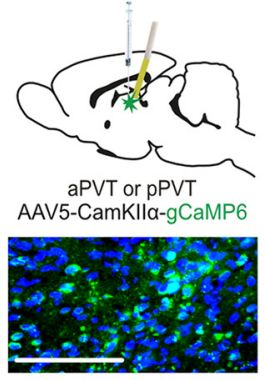

C

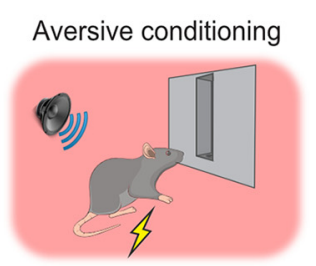

$\mathrm{CS} \rightarrow$ Shock
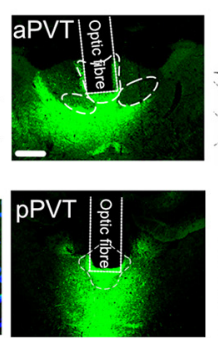

$\frac{-3.00 \mathrm{~mm}}{10}$
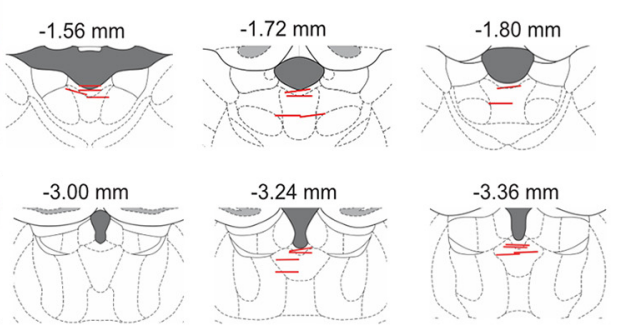

B
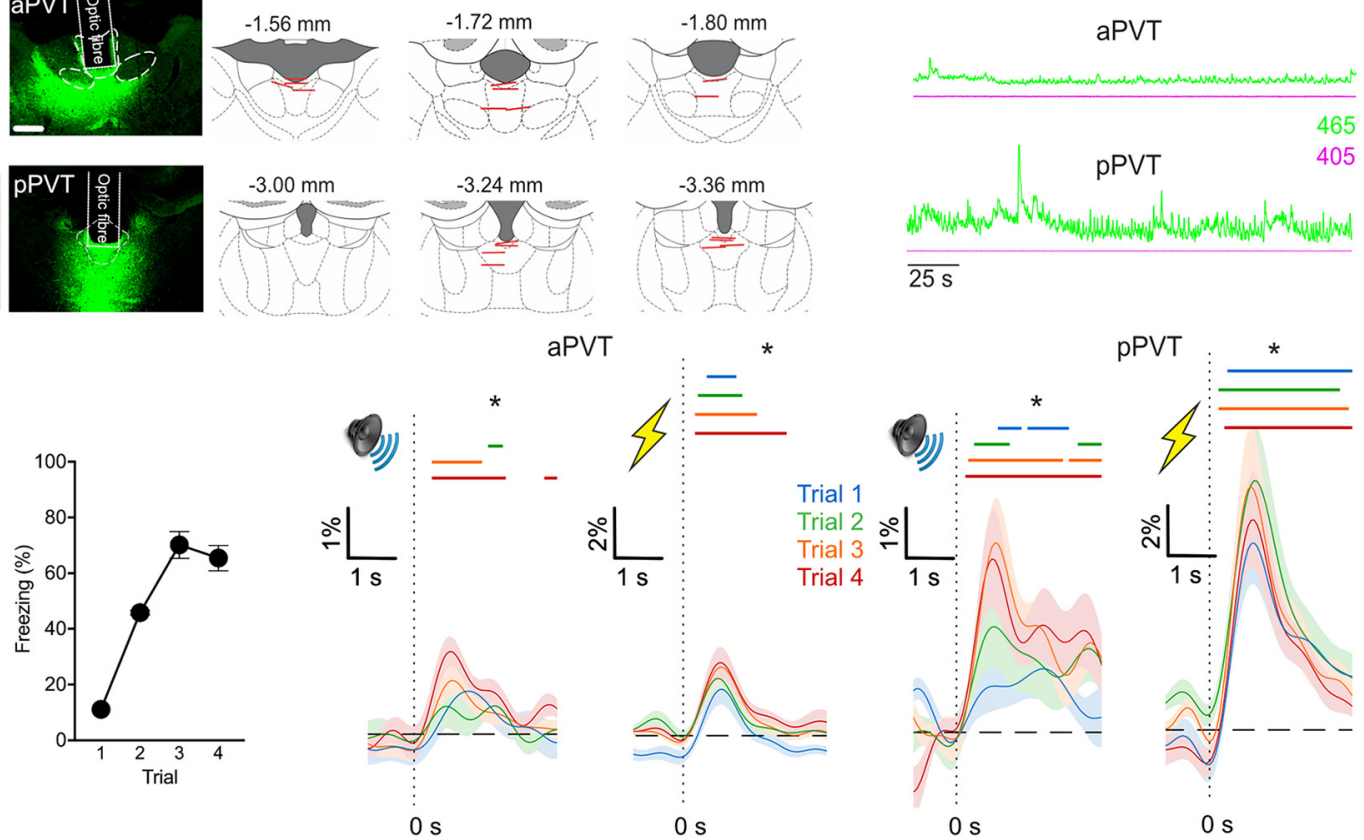

$0 \mathrm{~s}$

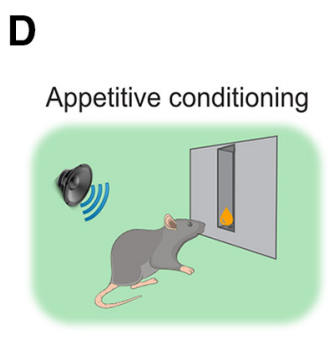

$\mathrm{CS} \rightarrow$ Sucrose

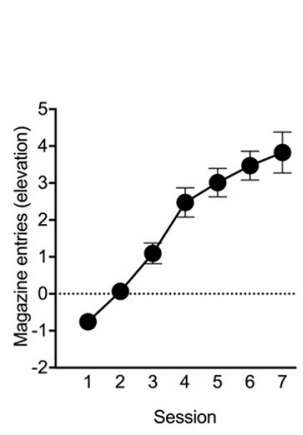

E
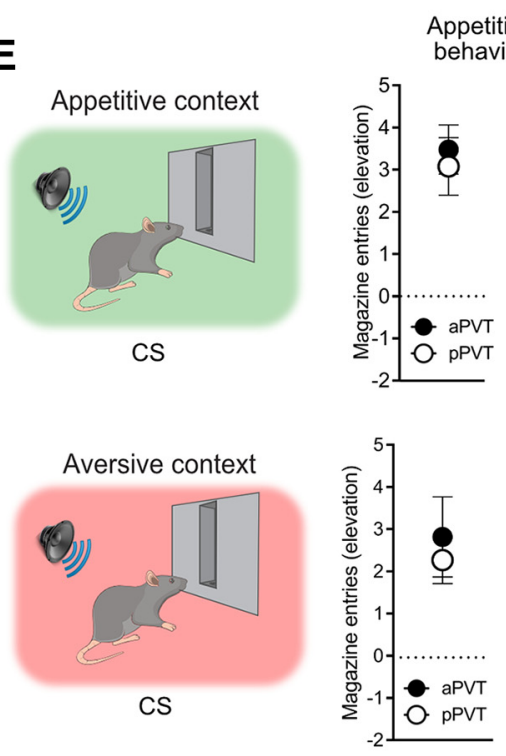
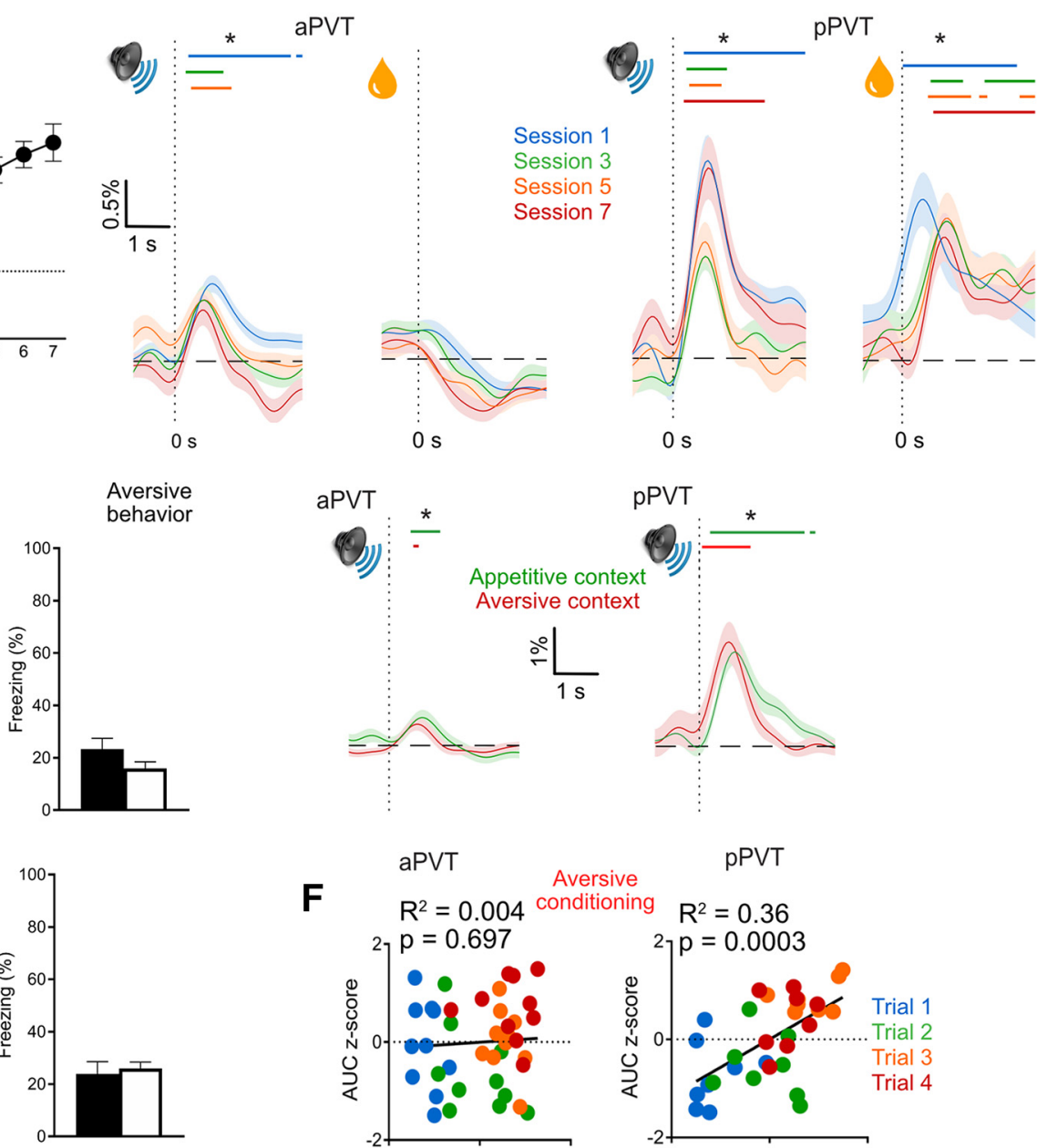

Aversive behavior
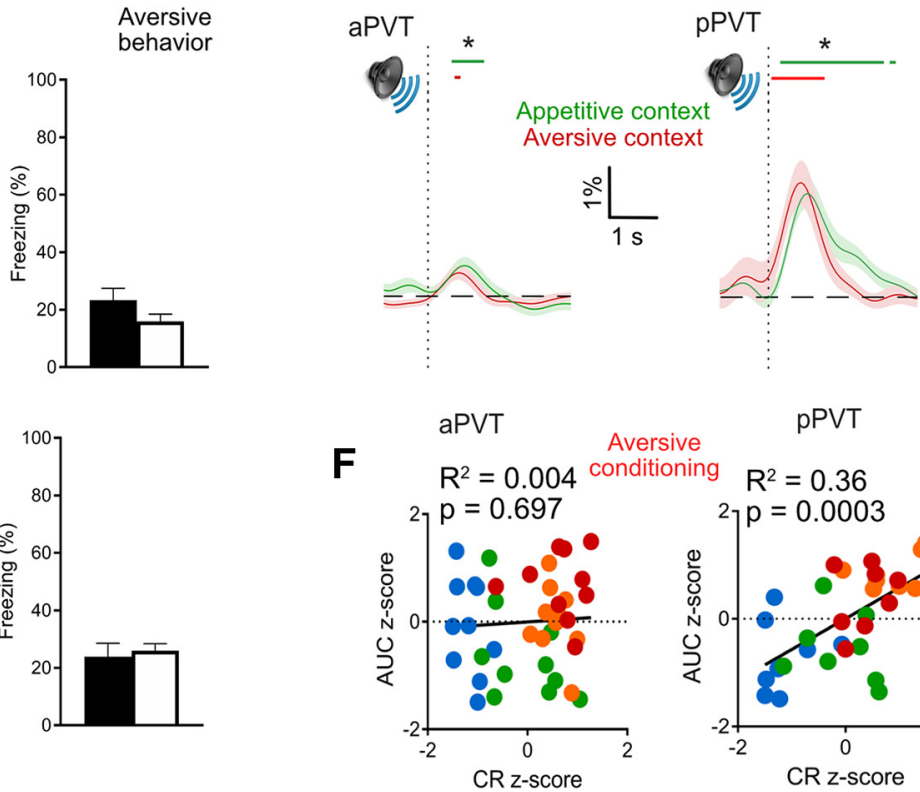

pPVT

Aversive

ning

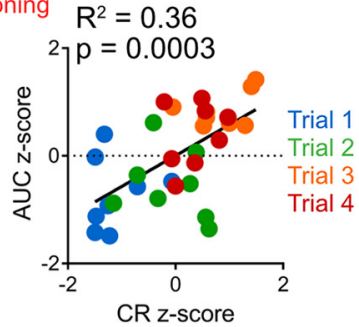

Figure 2. Experiment 2.A,AAV was used to express GCaMP6 in aPVT or pPVT in separate animals and fiber optic cannulae implanted into these regions. Representative images show native GCaMP expression and DAPI staining in PVT (green, native GCaMP; blue, DAPI; Scale bar, $100 \mu \mathrm{m}$ ), native GCaMP expression for aPVT and pPVT (Scale bar, $500 \mu \mathrm{m}$ ), as well as location of fiber tips for all animals included in the analyses. $\boldsymbol{B}$, Representative demodulated photometry traces from aPVT (during aversive training) and pPVT (during appetitive training). (Figure legend continues.) 
$\left(F_{(1,16)}=74.053, p<0.001\right)$. There was no difference between aPVT and pPVT groups $\left(F_{(1,16)}=1.367, p=0.259\right)$ and there was no interaction between Group and Day $\left(F_{(1,16)}=1.522, p=\right.$ $0.235)$. Similar to Experiment 1, aPVT showed robust and significant $\mathrm{Ca}^{2+}$ signals to CS presentations but not to reward consumption (Fig. 2D) and there was no obvious relationship between these signals and amount of training. pPVT showed robust and significant $\mathrm{Ca}^{2+}$ signals to both CS presentations and reward consumption (Fig. 2D).

\section{Test}

Rats were tested twice, once in the aversive conditioning context and once in the appetitive conditioning context. Rats expressed appetitive (i.e., magazine entries) and aversive (i.e., freezing) behavior in both contexts. For appetitive behavior, there was no main effect of Context $\left(F_{(1,16)}=1.440, p=0.248\right)$ showing similar levels of CS-elicited appetitive behaviors in both contexts. There was no main effect of Group $\left(F_{(1,16)}=0.310, p=0.585\right)$ with no Group $\times$ Context interaction $\left(F_{(1,16)}=0.015, p=\right.$ $0.904)$. For aversive behavior, there was no main effect of Context $\left(F_{(1,16)}=2.874, p=0.109\right)$, no main effect of $\operatorname{Group}\left(F_{(1,16)}=\right.$ $0.377, p=0.548)$ and no Group $\times$ Context interaction $\left(F_{(1,16)}=\right.$ 2.276, $p=0.151)$. The low level of aversive behaviors at test is likely because of the extended appetitive conditioning between aversive training and test. Fiber photometry showed that, like Experiment 1, both aPVT and pPVT exhibited significant CSevoked $\mathrm{Ca}^{2+}$ signals during tests (Fig. $2 E$ ), with no obvious differences in the magnitude of these signals across the contexts $\left(\right.$ AUC; $\operatorname{aPVT}: F_{(1,9)}=1.054, p=0.331$, pPVT: $F_{(1,7)}=0.064, p=$ $0.808)$.

\section{Experiment 3a-3c: chemogenetic inhibition of PVT (Experiment 3a), aPVT (Experiment 3b), or pPVT (Experiment 3c) on appetitive- to-aversive counterconditioning}

PVT shows robust activity during Pavlovian appetitive and aversive learning and then during expression of behavior under motivational conflict. So, next we studied the causal role of PVT in control of behavior under motivational conflict. The first question was does PVT control appetitive and/or aversive behaviors after counterconditioning? To answer this, rats received application of AAV encoding the inhibitory hM4Di DREADD $(n=8)$ or eYFP $(n=8)$ targeted across both the aPVT and pPVT (Experiment $3 a$ ). They received behavioral counterconditioning and we silenced PVT, via injection of the DREADD ligand CNO, before tests for appetitive and aversive behavior. The second question was, does the role for PVT in control of behavior vary across its anterior-posterior axis? To answer this, rats received application of AAV encoding the inhibitory hM4Di DREADD $(n=8)$ or eYFP $(n=8)$ targeted to either the aPVT (Experiment $3 \mathrm{~b})$ or

\footnotetext{
(Figure legend continued.) C, Rats received Pavlovian aversive conditioning and acquired fear responses to the CS. Photometry traces show mean $\pm \mathrm{SEM} \% \Delta \mathrm{F} / \mathrm{F}$ across trials for the $1 \mathrm{~s}$ prior and $3 \mathrm{~s}$ after $\mathrm{C} S$ and aversive US presentations. $\boldsymbol{D}$, Rats received Pavlovian appetitive conditioning and acquired magazine entries during the CS. Photometry traces show mean $\pm \mathrm{SEM} \% \Delta \mathrm{F} / \mathrm{F}$ across sessions for the $1 \mathrm{~s}$ prior and $3 \mathrm{~s}$ after $C \boldsymbol{S}$ and appetitive US presentations. $\boldsymbol{E}$, Rats were tested for appetitive and aversive behaviors in their respective training contexts. Photometry traces show mean $\pm \mathrm{SEM} \% \Delta \mathrm{F} / \mathrm{F}$ across trials for the $1 \mathrm{~s}$ prior and $3 \mathrm{~s}$ after $\mathrm{CS}$ presentations in each context. $\boldsymbol{F}$, Scatterplots of subject-normalized CS-elicited PVT activity (AUC $0.5-1.5 \mathrm{~s}$ from (S onset) and associated conditioned responding across initial aversive conditioning trials. ${ }^{*}$ Indicates lower bound $99 \% \mathrm{Cl}>0 \% \Delta \mathrm{F} / \mathrm{F}$ (colored lines above traces). aPVT, $n=$ 10; pPVT, $n=8$.
}

pPVT (Experiment 3c). Rats then received counterconditioning with silencing of aPVT or pPVT before tests.

\section{Histology}

For the PVT (Experiment 3a), 1 animal was excluded because of incorrect placements, leaving final group sizes of $n=8$ (eYFP) and $n=7$ (hM4Di). Figure $3 B$ shows representative hM4Di expression as well as location of hM4Di expression for each animal included in the analyses shown at $10 \%$ opacity. For aPVT (Experiment 3b), three animals were excluded because of incorrect placements, leaving final group sizes of $n=8$ (eYFP) and $n=5$ (hM4Di). Figure 3D shows representative hM4Di expression as well as location of hM4Di expression for each animal included in the analyses. For pPVT (Experiment 3c), 1 animal was excluded because of incorrect placement, leaving final group sizes of $n=7$ (eYFP) and $n=8$ (hM4Di). Figure $3 F$ shows representative hM4Di expression as well as location of hM4Di expression for each animal included in the analyses.

\section{Behavior}

For PVT (Experiment 3a), animals expressed robust CS-elicited magazine entries at the end of appetitive conditioning (Fig. 3C). CS-elicited magazine entries increased across conditioning days $\left(F_{(1,13)}=12.420, p=0.004\right)$. This learning did not differ between eYFP and hM4Di groups because there was no main effect of Group $\left(F_{(1,13)}=1.161, p=0.301\right)$ or Day $\times$ Group interaction $\left(F_{(1,13)}=1.218, p=0.290\right)$. During fear conditioning, freezing behavior also increased across conditioning trials $\left(F_{(1,13)}=\right.$ $45.599, p<0.001)$. This fear learning was the same across groups, there was no main effect of Group $\left(F_{(1,13)}=1.635, p=0.223\right)$ or Group $\times$ Trial interaction $\left(F_{(1,13)}=0.191, p=0.669\right.$; Fig. $3 C$, Training).

Rats were tested twice, once in the appetitive context and once in the aversive context (Fig. 3C, Test). For appetitive behavior, there were more CS-elicited magazine entries in the appetitive context than the aversive context $\left(F_{(1,13)}=14.833, p=0.002\right)$. Chemogenetic inhibition of PVT reduced CS-elicited magazine entries in the appetitive $\left(F_{(1,13)}=5.600, p=0.034\right)$ but not aversive context $\left(F_{(1,13)}=0.361, p=0.558\right)$. There were no Group $\times$ Trial interactions in either context for magazine entries $\left(F_{(1,13)}<0.549, p>0.471\right)$. CS-elicited freezing was similar in both contexts $\left(F_{(1,13)}=1.410, p=0.256\right)$ and chemogenetic inhibition of PVT increased freezing in both contexts $\left(F_{(1,13)}=\right.$ 7.141, $p=0.019)$. There was a Group $\times$ Trial interaction for freezing in the appetitive context $\left(F_{(1,13)}=5.813, p=0.031\right)$ showing higher initial freezing in hM4Di group across the first two blocks $\left(F_{(1,13)}=10.351, p=0.007\right)$ but no interaction in the aversive context $\left(F_{(1,13)}=4.261, p=0.060\right.$; Fig. $3 C$, insets $)$.

For aPVT (Experiment $3 \mathrm{~b}$ ), animals expressed robust CSelicited magazine entries at the end of appetitive conditioning (Fig. 3E, Training). CS-elicited magazine entries increased across conditioning days $\left(F_{(1,11)}=38.009, p<0.001\right)$ and did not differ between eYFP and hM4Di groups (no main effect of Group $F_{(1,11)}=$ $1.059, p=0.326$ or Day $\times$ Group interaction $F_{(1,11)}=0.490, p=$ $0.498)$. During fear conditioning, CS-elicited freezing increased across conditioning trials $\left(F_{(1,11)}=51.807 p<0.001\right)$ and was the same across groups (no main effect of Group: $F_{(1,11)}=0.532, p=$ 0.481 , or Group $\times$ Trial interaction: $F_{(1,11)}=0.178, p=0.681$ ). On test (Fig. 3E, Test), magazine entries were similar in the appetitive and aversive contexts $\left(F_{(1,11)}=0.642, p=0.440\right)$ and aPVT chemogenetic inhibition had no effect in either context (appetitive context: $F_{(1,11)}=0.100, p=0.758$; aversive context: $\left.F_{(1,11)}=0.106, p=0.751\right)$. Levels of freezing were similar in both 
A

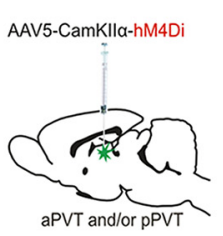

Training

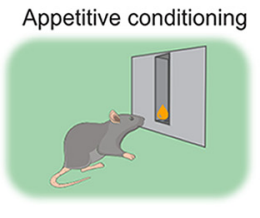

$c s \rightarrow$ Sucrose

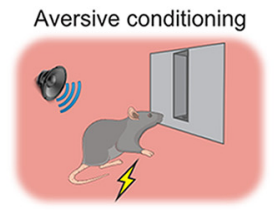

cs $\rightarrow$ Shock

C

B Anterior and posterior PVT
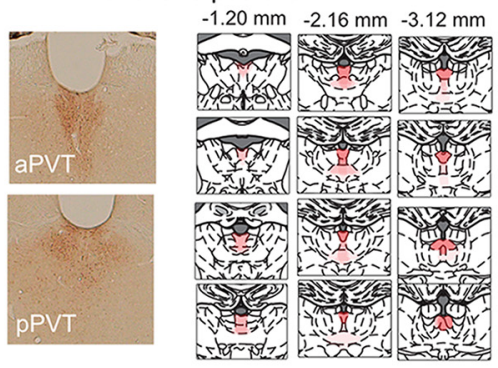

D Anterior PVT
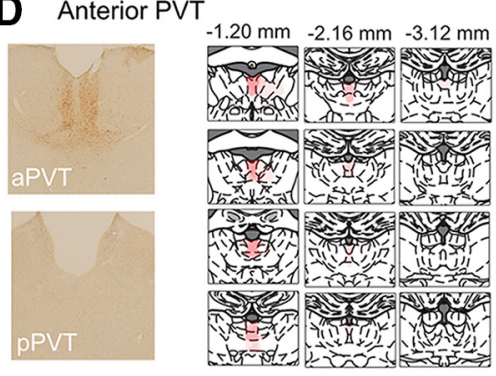

F Posterior PVT
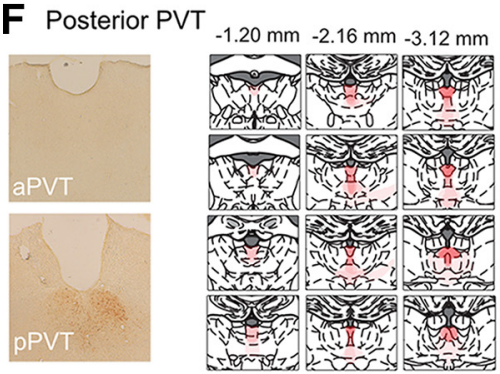

E

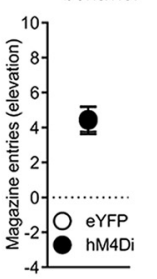

Test

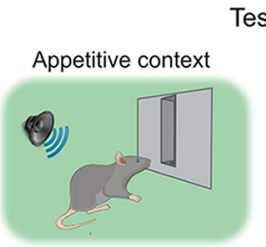

CS

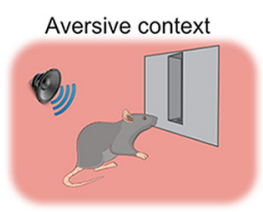

CS
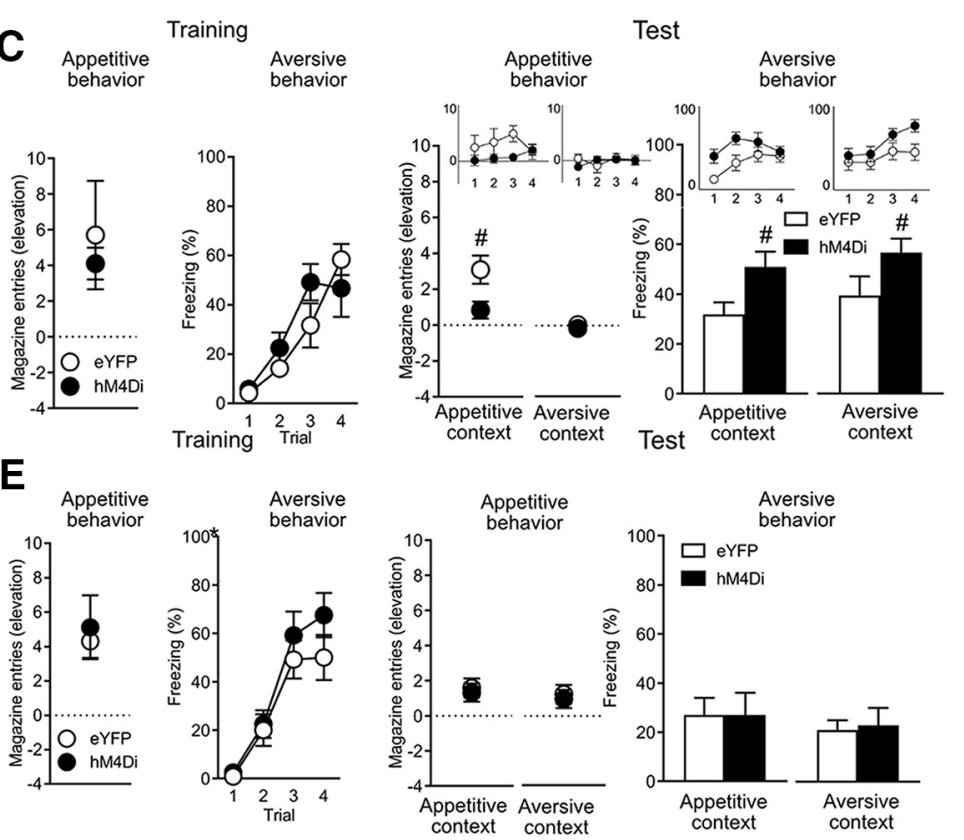

Test
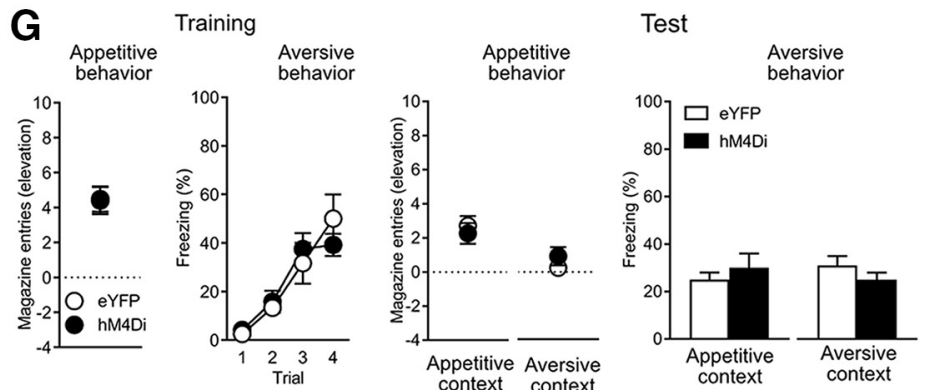

Training
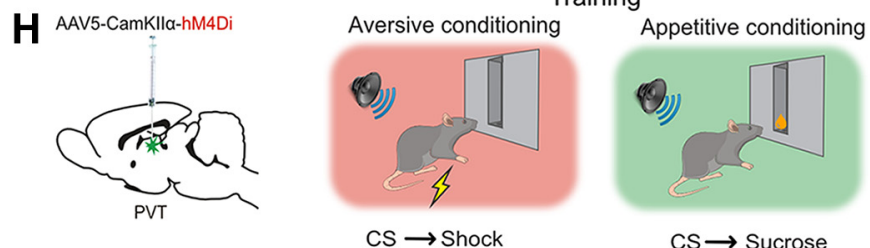

$\mathrm{cs} \rightarrow$ Sucrose

$\mathbf{J}$

I Anterior and posterior PVT
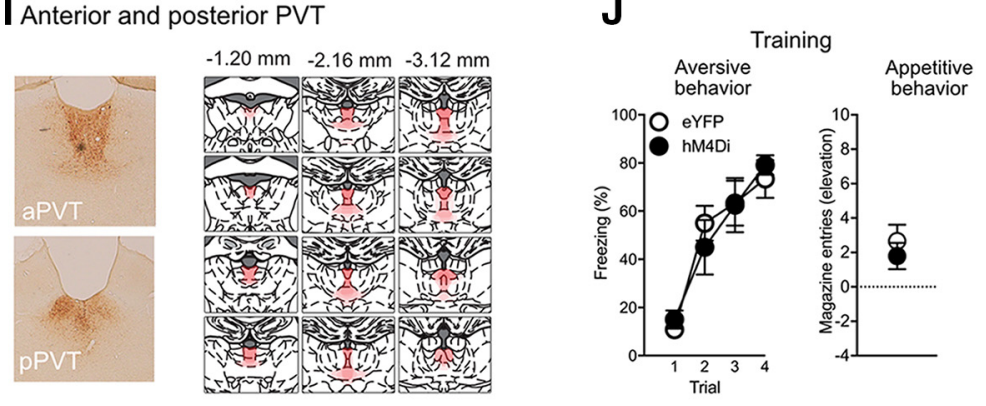

Test

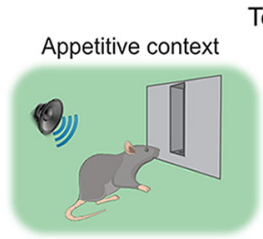

cs

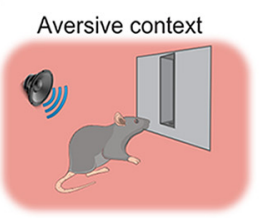

CS

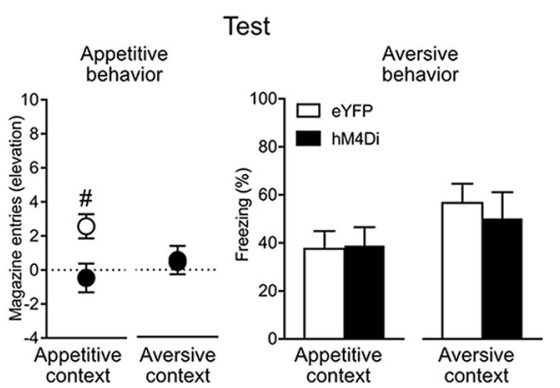

Figure 3. $\quad \boldsymbol{A}, \mathrm{AAV}$ was used to express eYFP or hM4Di in PVT, aPVT, or pPVT. Rats then received appetitive to aversive counterconditioning. $\boldsymbol{B}$, Experiment 3 a. Representative images showing hM4Di expression for whole PVT and placement map with each animal represented at 10\% opacity (eYFP, $n=8 ; \mathrm{hM} 4 \mathrm{Di}, n=7$ ). C, Mean \pm SEM appetitive responses at the end of appetitive conditioning, mean \pm SEM aversive responses during aversive conditioning, and mean \pm SEM appetitive and aversive responses on tests. Chemogenetic (Figure legend continues.) 
contexts $\left(F_{(1,11)}=0.429, p=0.526\right)$ and aPVT chemogenetic inhibition had no effect on freezing in either context (appetitive context: $F_{(1,11)}=0.001, p=0.975$; aversive context: $F_{(1,11)}=$ $0.050, p=0.827)$. There were no Group $\times$ Trial interactions on either test $\left(F_{(1,11)}<0.009, p>0.925\right)$.

For pPVT (Experiment 3c), CS-elicited magazine entries increased across conditioning days $\left(F_{(1,13)}=39.355, p<0.001\right)$ and did not differ between eYFP and hM4Di groups as there was no main effect of Group $\left(F_{(1,13)}=0.905, p=0.359\right)$ or Day $\times$ Group interaction $\left(F_{(1,13)}=0.309, p=0.587\right.$; Fig. 3G, Training). During fear conditioning, freezing behavior increased across trials $\left(F_{(1,13)}=40.902, p<0.001\right)$ and was the same across groups (no main effect of group: $F_{(1,13)}=0.010, p=0.922$, or Group $\times$ Trial interaction: $F_{(1,13)}=0.473, p=0.504$; Fig. $3 G$, Test). Magazine entries were higher in the appetitive than aversive contexts $\left(F_{(1,13)}=16.768, p=0.001\right)$ but pPVT chemogenetic inhibition had no effect in the appetitive $\left(F_{(1,13)}=0.284, p=0.603\right)$ or aversive context $\left(F_{(1,13)}=1.190, p=0.295\right)$. Levels of freezing were similar in both contexts $\left(F_{(1,13)}=0.009, p=0.926\right)$ and chemogenetic inhibition of pPVT had no effect in either context (appetitive context: $F_{(1,13)}=0.565, p=0.466$; aversive context: $\left.F_{(1,13)}=1.608, p=0.227\right)$. There were no Group $\times$ Trial interactions on either test $\left(F_{(1,13)}<0.138, p>0.760\right)$.

\section{Experiment 4: chemogenetic inhibition of PVT on aversive- to-appetitive counterconditioning}

Experiment 3 showed that chemogenetic inhibition of the PVT, but not aPVT or pPVT alone, disrupted appetitive behavior and increased aversive behavior under motivational conflict. Our fiber photometry data showed that PVT activity in this task was similar regardless of the origin of this conflict (i.e., transforming a reward signal into a danger signal or vice versa). So, we examined whether the effects of PVT inhibition were also independent of the origin of conflict. To do this, we expressed hM4Di $(n=8)$ or eYFP $(n=8)$ in PVT and trained rats in an aversive-toappetitive counterconditioning procedure. We silenced PVT before tests for appetitive and aversive behavior.

\section{Histology}

One animal was excluded, leaving final group sizes of $n=8$ (eYFP) and $n=7$ (hM4Di). Figure 3I shows representative hM4Di expression in PVT as well as location of hM4Di expression for each animal included in the analyses.

\footnotetext{
$\leftarrow$

(Figure legend continued.) silencing of PVT on test reduced appetitive behavior and increased aversive behavior. Insets, Appetitive and aversive responses across four blocks of two test trials. D, Experiment $3 b$. Representative images showing hM4Di expression for aPVT and pPVT for the aPVT experiment and placement map with each animal represented at $10 \%$ opacity (eYFP, $n=$ $8 ; \mathrm{hM} 4 \mathrm{Di}, n=5) . \boldsymbol{E}$, Mean \pm SEM appetitive responses at the end of appetitive conditioning, mean \pm SEM aversive responses during aversive conditioning, and mean \pm SEM appetitive and aversive responses on tests. Chemogenetic silencing of aPVT on test had no effect on appetitive or aversive behavior. $\boldsymbol{F}$, Experiment 3c. Representative images showing hM4Di expression for aPVT and pPVT for the PPVT experiment and placement map with each animal represented at $10 \%$ opacity (eYFP, $n=7 ; \mathrm{hM} 4 \mathrm{Di}, n=8$ ). G, Mean \pm SEM appetitive responses at the end of appetitive conditioning, mean \pm SEM aversive responses during aversive conditioning, and mean \pm SEM appetitive and aversive responses on tests. Chemogenetic silencing of pPVT on test had no effect on appetitive or aversive behavior. $\boldsymbol{H}$, Experiment 4 . AAV was used to express eYFP or hM4Di in PVT, rats then received aversive to appetitive counterconditioning. I, Representative images showing hM4Di expression for PVT and placement map with each animal represented at $10 \%$ opacity (eYFP, $n=8 ; \mathrm{hM} 4 \mathrm{Di}, n=7$ ). $\boldsymbol{J}$, Mean \pm SEM aversive responses during aversive conditioning, mean \pm appetitive SEM responses at the end of appetitive conditioning, and mean \pm SEM appetitive and aversive responses on tests. $\# p<0.05$.
}

\section{Behavior}

Rats expressed robust CS-elicited freezing behavior at the end of aversive conditioning (Fig. 3J, Training). CS-elicited freezing responses increased across conditioning trials $\left(F_{(1,13)}=150.052\right.$, $p<0.001)$ and was the same for eYFP and hM4Di groups because there was no main effect of $\operatorname{Group}\left(F_{(1,13)}=0.081, p=0.780\right)$ or Day $\times$ Group interaction $\left(F_{(1,13)}=0.055, p=0.818\right)$. Magazine approach behavior also increased across appetitive conditioning days $\left(F_{(1,13)}=56.237, p<0.001\right)$. This was the same across groups and there was no main effect of Group $\left(F_{(1,13)}=0.565\right.$, $p=0.466)$ or Group $\times$ Trial interaction $\left(F_{(1,13)}=1.347, p=\right.$ $0.267)$. On test (Fig. $3 H$, Test), magazine entries were similar in the appetitive and aversive context $\left(F_{(1,13)}=1.950, p=0.186\right)$ but PVT chemogenetic inhibition reduced magazine entries in the appetitive $\left(F_{(1,13)}=7.659, p=0.016\right)$ but not aversive context $\left(F_{(1,13)}=0.020, p=0.890\right)$. Levels of freezing were greater in the aversive than appetitive context $\left(F_{(1,13)}=7.245, p=0.018\right)$ but PVT chemogenetic inhibition had no effect in either context $\left(F_{(1,13)}=0.472, p=0.504\right)$. There were no Group $\times$ Trial interactions for magazine entries or freezing behavior in either context $\left(F_{(1,13)}<2.347, p>0.150\right)$.

Experiments 5a-5d: chemogenetic inhibition of PVT during appetitive (Experiments 5a and 5b) or aversive (Experiment 5c) memory retrieval and on locomotor activity

These findings show a role for PVT in behavioral control during conflict. We next examined the effects of PVT chemogenetic inhibition on appetitive and aversive behaviors when these were assessed in the absence of conflict. To do so, we expressed eYFP $(n=8)$ or hM4Di $(n=8)$ in PVT (aPVT and pPVT) and trained and tested rats for appetitive conditioning based on a liquid (Experiment 5a) or pellet (Experiment 5b) sucrose reward. Experiment $5 \mathrm{a}$ was identical to the procedure used in counterconditioning whereas Experiment 5b used a different, but equally effective, conditioning procedure to assess whether the results of Experiment $5 \mathrm{a}$ generalized to other forms of appetitive conditioning. We silenced PVT before tests for appetitive behavior. In Experiment $5 \mathrm{c}$, we expressed eYFP $(n=8)$ or hM4Di $(n=8)$ in PVT (aPVT and pPVT) and trained and tested rats for Pavlovian fear conditioning. We silenced PVT before test for fear. The question of interest was does PVT silencing affect expression of appetitive or aversive behavior in the absence of conflict? In addition, because our measures of appetitive behavior (magazine entries) and aversive behavior (freezing) can be influenced by changes in locomotor activity and because $\mathrm{CNO}$ injection can affect locomotor activity under some conditions (MacLaren et al., 2016), we assessed the effects of PVT chemogenetic inhibition on locomotor activity in an open field in Experiment 5d. Finally, we verified that $\mathrm{CNO}$ injection in hM4Di-expressing animals achieved neuronal inhibition by examining c-Fos protein expression in PVT.

\section{Histology}

For Experiment $5 \mathrm{a}$, all animals had correct AAV placements, leaving final group sizes of $n=8$ (eYFP) and $n=8$ (hM4Di). Figure $4 B$ shows location of hM4Di expression for each animal (at 10\% opacity) included in the analyses. For Experiment 5b, one animal had misplaced AAV expression so final group sizes were $n=8$ (eYFP) and $n=7$ (hM4Di). Figure $4 C$ shows location of hM4Di expression for each animal (at 10\% opacity) included in the analyses. For Experiment $5 \mathrm{c}$, all animals had correct AAV placements, leaving final group sizes of $n=8$ (eYFP) and $n=8$ 
A

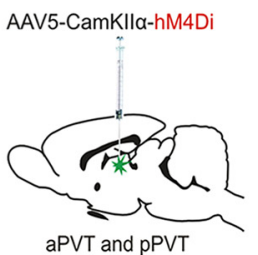

B

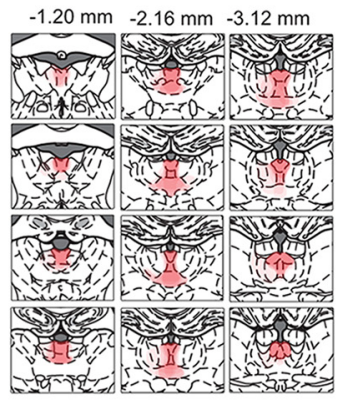

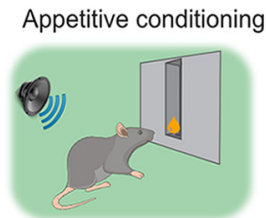

CS $\rightarrow$ Sucrose

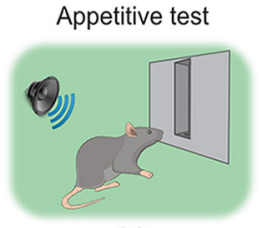

CS

C
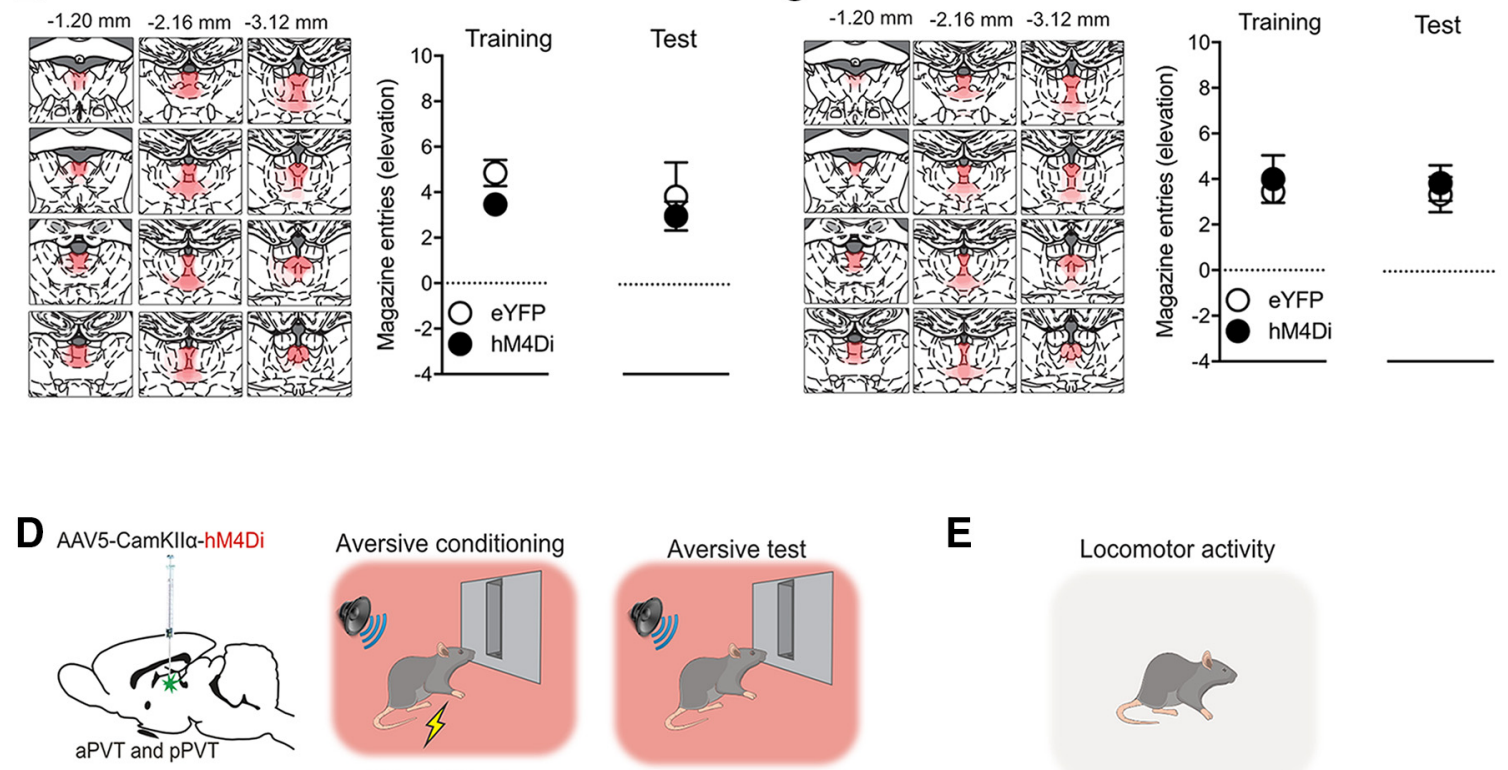

$-2.16 \mathrm{~mm} \quad-3.12 \mathrm{~mm}$

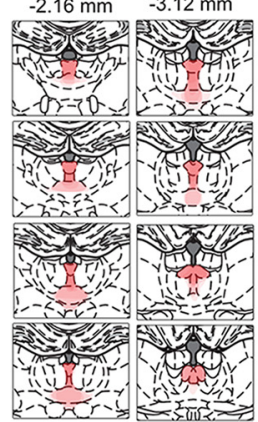

$\mathbf{F}$

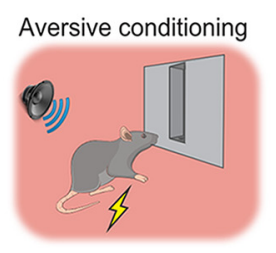

$\mathrm{CS} \rightarrow$ Shock

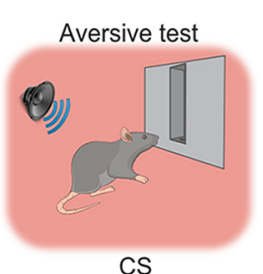

CS
$\mathbf{E}$

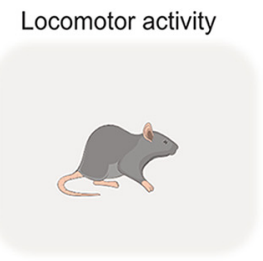

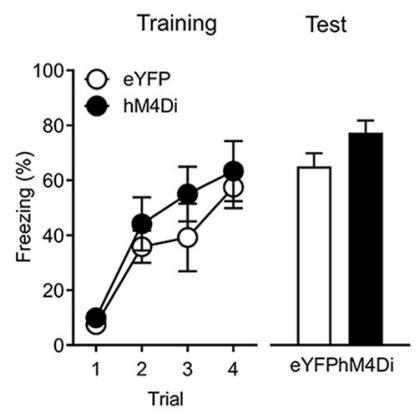
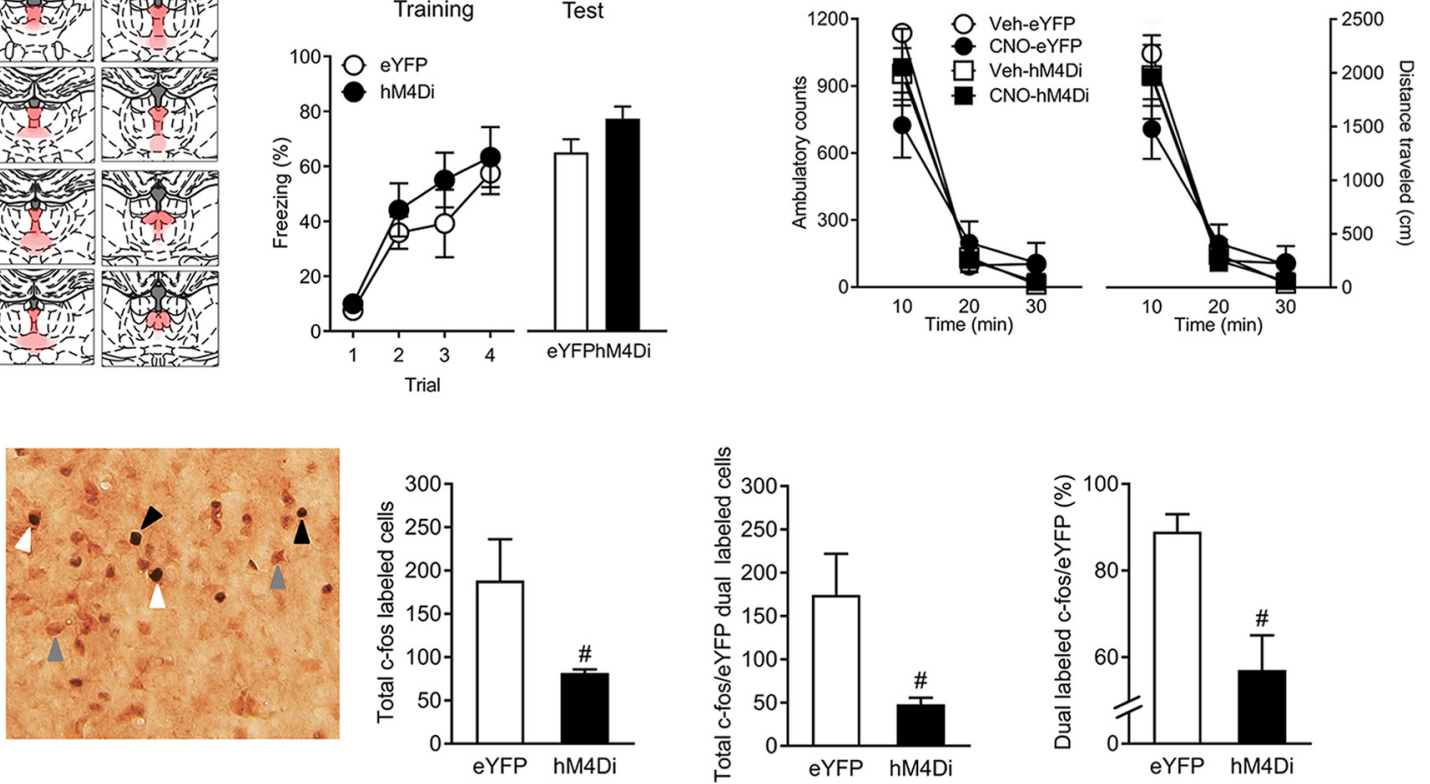

Figure 4. A, Experiments $5 \mathrm{a}$ and $5 \mathrm{~b}$. AAV was used to express eYFP or $\mathrm{hM4Di}$ in PVT and rats then received appetitive conditioning using liquid (Experiment $5 \mathrm{a}$ ) or pellet (Experiment $5 \mathrm{~b}$ ) reward. $B$, Experiment 5a. Placement map showing hM4Di expression with each animal represented at 10\% opacity, eYFP $(n=8)$ or hM4Di $(n=8)$. Mean \pm SEM appetitive responses at the end of appetitive conditioning and during test. Chemogenetic silencing of PVT had no effect on appetitive behaviors. C, Experiment 5b. Placement map showing hM4Di expression with each animal represented at $10 \%$ opacity in PVT, eYFP $(n=8)$ or hM4Di $(n=7)$. Mean \pm SEM appetitive responses at the end of appetitive conditioning and during test. Chemogenetic silencing of PVT on test had no effect on appetitive behaviors. D, Experiment $5 c$. AAV was used express eYFP $(n=8)$ or hM4Di $(n=8)$ in PVT and rats then received aversive conditioning. Placement map showing hM4Di expression with each animal represented at $10 \%$ opacity. Mean \pm SEM aversive responses during aversive conditioning and during test. Chemogenetic silencing of PVT had no effect on aversive behaviors. $\boldsymbol{E}$, Experiment $5 \mathrm{~d}$. Chemogenetic silencing of PVT also had no effect on locomotor activity when assessed in an open field. $\boldsymbol{F}$, Experiment 6 . c-Fos immunohistochemistry was used to verify PVT chemogenetic inhibition, group hM4Di $n=8$, eYFP $n=8$. Example of single Fos (black arrowhead), single eYFP (gray arrowhead), and dual-labeled c-Fos/eYFP neurons (white arrowhead) in PVT. Mean \pm SEM numbers of total c-Fos, total dual-labeled c-Fos/eYFP, and percentage dual-labeled c-Fos/eYFP neurons in PVT after CNO injection. \#p $<0.05$. 
(hM4Di). Figure $4 D$ shows location of hM4Di expression for each animal included in the analyses.

\section{Behavior}

In Experiment 5a, at the end of appetitive conditioning, animals showed robust $\mathrm{CS}$-elicited magazine entries (Fig. 4A). On the last day of training, there was a modest significant difference between groups $\left(F_{(1,14)}=4.850, p=0.045\right)$, with eYFP group making more magazine entries than the hM4Di group. Regardless, on test, magazine responses remained high and there was no effect of PVT chemogenetic inhibition $\left(F_{(1,14)}=0.278, p=0.606\right)$. There was also no interaction between Day (last day of training vs test) and Group $\left(F_{(1,14)}=0.087, p=0.772\right)$ showing that PVT chemogenetic silencing did not affect appetitive behavior. In Experiment 5b (Fig. 4C), there was no difference in CS-elicited magazine entries between groups on the last day of training $\left(F_{(1,14)}=0.262, p=0.617\right)$. During test, magazine entries remained high and there was again no effect of PVT chemogenetic inhibition $\left(F_{(1,14)}=0.213, p=0.652\right)$. There was also no interaction between Day (last day of training vs test) and Group $\left(F_{(1,13)}=0.002, p=0.965\right)$ showing that PVT chemogenetic silencing did not affect appetitive behavior.

In Experiment 5c, during fear conditioning (Fig. 4D), freezing behavior increased across conditioning trials $\left(F_{(1,14)}=63.661\right.$, $p<0.001$ ). This fear learning was the same across groups (no main effect of group: $F_{(1,14)}=0.751, p=0.401$, or Group $\times$ Trial interaction: $\left.F_{(1,14)}=0.185, p=0.674\right)$. On test, freezing levels remained high and there was no effect of PVT chemogenetic inhibition $\left(F_{(1,14)}=3.484, p=0.083\right)$.

In Experiment 5d, we assessed locomotor activity in hM4Di $(n=7)$ and eYFP $(n=8)$ animals after injection of $\mathrm{CNO}$ and vehicle (within-subjects, counterbalanced test order; Fig. 4E). There was no main effect of Drug (CNO vs Vehicle), Group (hM4Di vs eYFP), or Drug $\times$ Group interaction on overall ambulatory counts or distance traveled (largest: $F_{(1,13)}=2.922, p=$ $0.111)$. Linear trend analysis showed that both ambulatory counts $\left(F_{(1,13)}=101.775, p<0.001\right)$ and distance traveled $\left(F_{(1,13)}\right.$ $=121.294, p<0.001)$ decreased significantly across the $30 \mathrm{~min}$ sessions but these were the same for all groups (largest: $F_{(1,13)}=$ $1.328, p=0.270)$.

Finally, to confirm the cellular effects of PVT chemogenetic inhibition we examined c-Fos protein expression in PVT after injection of CNO in hM4Di $(n=8)$ and $\operatorname{eYFP}(n=8)$-expressing animals in Experiment 6. Figure $4 F$ shows a representative PVT section with hM4Di-expressing, c-Fos-expressing, and duallabeled hM4Di/c-Fos-expressing neurons. As expected (Choi and McNally, 2017), CNO injection caused an $\sim 50-60 \%$ reduction in PVT c-Fos protein expression. There was a significant reduction in total c-Fos labeled cells $\left(F_{(1,14)}=4.966, p=0.043\right)$, total dual-labeled c-Fos/eYFP cells $\left(F_{(1,14)}=6.925, p=0.020\right)$, and percentage of c-Fos neurons dual-labeled with eYFP cells $\left(F_{(1,14)}\right.$ $=5.535, p=0.034)$ for hM4Di compared with eYFP animals.

\section{Discussion}

Here we studied the role of PVT in motivational conflict. We used Pavlovian counterconditioning to imbue a CS with mixed motivational valence, eliciting both appetitive and aversive behaviors. We combined this with fiber photometry and chemogenetics to study how PVT activity relates to the learning and resolution of motivational conflict. There are two key findings. First, although PVT responds to appetitive and aversive events as well as their predictors, there are significant differences in these responses across its anterior-posterior axis. Second, despite these differ- ences, the combined function of both aPVT and pPVT is necessary for behavioral control during motivational conflict.

\section{Fiber photometry of PVT during counterconditioning}

Fiber photometry showed PVT $\mathrm{Ca}^{2+}$ signals to sucrose reward, footshock, as well as to CSs that predicted these. We also found that PVT Ca ${ }^{2+}$ signals during CS presentations reliably predicted the emergence of appetitive and aversive conditioned responses. Interestingly, our results were similar regardless of the order of appetitive and aversive conditioning. These findings extend those recently reported for PVT fiber photometry in head fixed mice during appetitive and aversive Pavlovian conditioning (Zhu et al., 2018). Moreover, like Zhu et al. (2018) we detected an ordinal relationship between CS-evoked PVT Ca ${ }^{2+}$ signals and the emergence of appetitive learning and we show that this relationship is also observed in de novo aversive learning. These findings have been interpreted to mean that PVT determines stimulus salience during associative learning.

However, a key finding here is that there are regional differences across the anterior-posterior axis of the PVT. Notably, although both aPVT and pPVT showed $\mathrm{Ca}^{2+}$ signals to the CSs and footshock, only pPVT was responsive to sucrose reward. In addition, pPVT but not aPVT showed an ordinal relationship between CS-evoked $\mathrm{Ca}^{2+}$ signals and emergence of conditioned responding. Finally, CS-evoked $\mathrm{Ca}^{2+}$ signals in pPVT were significantly better than aPVT signals in predicting emergence of conditioned responding, regardless of its valence. These regional differences between aPVT and pPVT are not surprising based on their differences in anatomical connectivity (Kirouac, 2015; Dong et al., 2017). However, the lack of detectable $\mathrm{Ca}^{2+}$ signals to reward delivery in the aPVT and the status of aPVT as a significantly inferior predictor of both appetitive and aversive responding is surprising because aPVT has been strongly implicated in consuming and responding to food and drug rewards (Browning et al., 2014; Barson et al., 2015; Do-Monte et al., 2017; Cheng et al., 2018). These differences suggest that any role for PVT in stimulus salience during learning likely varies across its anteriorposterior axis.

\section{PVT and behavioral control under conflict}

Although showing $\mathrm{Ca}^{2+}$ signals to sucrose delivery, footshock, as well as their predictors, PVT was not necessary for expression of appetitive or aversive behaviors. That is, chemogenetic inhibition of PVT had no effect on the expression of these behaviors when they were assessed independently. It is unlikely that this failure was because of our experimental conditions. Similar null effects were reported previously for appetitive (Choi and McNally, 2017; Zhu et al., 2018) and aversive behaviors (Li et al., 2014; Choi and McNally, 2017). For example, Zhu et al. (2018) showed that optogenetic inhibition of PVT during CS presentations had no effect on the expression of well learned Pavlovian appetitive behavior in mice even though PVT neurons showed robust increases in firing rates and $\mathrm{Ca}^{2+}$ signals during CS presentations. This lack of effect of PVT inhibition on CS-elicited behavior suggests that the role for PVT in behavior extends beyond stimulus salience.

Rather, here and previously (Li et al., 2014; Choi and McNally, 2017; Zhu et al., 2018), PVT appears especially important for behavioral control when appetitive and aversive behaviors are elicited at the same time and the animal must select between them, i.e., during conflict. Under these conditions, PVT silencing reliably disrupted behavior. Interestingly, despite differences between aPVT and pPVT in their responses to reward and danger, 
silencing either aPVT or pPVT alone had no significant effects, suggesting that their combined function is necessary when appetitive and aversive behaviors are in conflict.

One locus for this behavioral control could be at the level of selection between neural circuits for conditioned responding. PVT has extensive projections to amygdala circuits controlling the freezing response and ventral striatal circuits controlling appetitive conditioned approach behavior (Kirouac, 2015; Dong et al., 2017). Animals cannot simultaneously freeze and approach the magazine for reward, so PVT could be essential to determining which of these behaviors dominates by selecting between the neural circuits controlling incompatible conditioned responses. So, after PVT silencing, one response should decrease as the other increased. Indeed, a reciprocal relationship between appetitive and aversive behaviors was observed under some conditions (Experiment 3) but it was not observed under others (Experiment 4). This finding suggests at least partially dissociable PVT control of appetitive and aversive behavior during conflict.

An alternative locus is at the level of motivational state whereby PVT controls underlying appetitive and aversive tendencies during conflict. This possibility is attractive because it may explain why aPVT and pPVT are both necessary for behavioral control. For example, aPVT and pPVT project to the dorsomedial versus ventromedial accumbens shell, respectively (Dong et al., 2017). These two accumbens shell regions are differentially implicated in appetitive (dorsomedial shell) versus aversive (ventromedial shell) motivation (Al-Hasani et al., 2015). Within accumbens shell, PVT projections converge and interact with inputs from the ventral hippocampus (Perez and Lodge, 2018). This places PVT at a key location in a classic "conflict" neurocircuitry. The ventral hippocampus is part of a behavioral inhibition system that suppresses behavior during conflict (Gray and McNaughton, 2000; Corr and McNaughton, 2012; Corr, 2013; Bach et al., 2014; O'Neil et al., 2015; Ito and Lee, 2016). Interactions between PVT and ventral hippocampal inputs in accumbens shell are necessary for downstream activity, including in midbrain dopamine neurons (Perez and Lodge, 2018). So, PVT, via its interaction with ventral hippocampus in accumbens shell, is well placed to control appetitive and aversive motivational states during conflict.

\section{Methodological considerations}

There are three methodological issues worth considering. First, fiber photometry yields a population fluorescence signal. So, we cannot make any claims about the extent of overlap, at the single neuron level, of responsivity to the CS, appetitive US, or aversive US. Nonetheless, recent findings using single-unit recordings in PVT during a similar task in head-fixed mice showed that the vast majority of neurons shared responsiveness to CSs as well as appetitive and aversive USs (Zhu et al., 2018).

Second, we used CNO as the DREADD ligand. This raises concerns about specificity (MacLaren et al., 2016) as well as offtarget actions because of its back metabolism to clozapine (Gomez et al., 2017). We assessed nonspecific effects of DREADD expression and $\mathrm{CNO}$ injection on locomotor activity. Consistent with our past work (Yau and McNally, 2015; Sengupta et al., 2016; Choi and McNally, 2017; Gibson et al., 2018), there were none. We also showed that $\mathrm{CNO}$ injection in DREADD-expressing animals had no effect on expression of appetitive or aversive behaviors when these were assessed independently of each other. Finally, CNO injection in DREADD or eYFP-expressing animals had no effect on appetitive or aversive behavior when DREADD expression was restricted to either the aPVT or pPVT. So, there was no evidence here that DREADD expression, $\mathrm{CNO}$ injection or both DREADD expression and CNO injection, were sufficient to alter behavior. Rather, effects were only observed when both aPVT and pPVT were chemogenetically silenced and behavior was assessed under motivational conflict.

Finally, some features of the behavioral design are worth comment. We used separate contexts for appetitive and aversive training. This was done to ensure that there would be measurable levels of appetitive and aversive behaviors. It is possible that PVT manipulations affected contextual processing rather than behavioral selection but this is unlikely because we have previously shown that PVT silencing does not affect contextual control over fear behavior (Choi and McNally, 2017). In addition, the profile of PVT $\mathrm{Ca}^{2+}$ signals here were similar to those seen in mice using single context designs. Moreover, in the experiments reported here, there was evidence for intact contextual processing but disrupted behavioral expression under conflict (Experiment 4). It might also be suggested that PVT silencing did not affect expression of fear when it was assessed alone because levels of fear were higher when assessed in the absence of conflict. However, we have previously shown no effect of PVT silencing on the expression of freezing across a range of levels of fear, suggesting that the level of fear does not determine the effect of PVT silencing (Choi and McNally, 2017).

\section{Conclusions}

Resolution of motivational conflict is fundamental to adaptive behavior. Here we identify PVT as critical to behavioral control under motivational conflict. We suggest that PVT is essential to controlling the strength of appetitive and aversive behaviors when they are in conflict. This role is likely linked to PVT's location as an interface between viscerosensory hypothalamic and brainstem centers for feeding and energy balance, and limbic, striatal, and prefrontal circuits for response selection and behavioral control.

\section{References}

Al-Hasani R, McCall JG, Shin G, Gomez AM, Schmitz GP, Bernardi JM, Pyo CO, Park SI, Marcinkiewcz CM, Crowley NA, Krashes MJ, Lowell BB, Kash TL, Rogers JA, Bruchas MR (2015) Distinct subpopulations of nucleus accumbens dynorphin neurons drive aversion and reward. Neuron 87:1063-1077.

Armbruster BN, Li X, Pausch MH, Herlitze S, Roth BL (2007) Evolving the lock to fit the key to create a family of G-protein-coupled receptors potently activated by an inert ligand. Proc Natl Acad Sci U S A 104:5163-5168.

Bach DR, Guitart-Masip M, Packard PA, Miró J, Falip M, Fuentemilla L, Dolan RJ (2014) Human hippocampus arbitrates approach-avoidance conflict. Curr Biol 24:1435.

Barson JR, Ho HT, Leibowitz SF (2015) Anterior thalamic paraventricular nucleus is involved in intermittent access ethanol drinking: role of orexin receptor 2. Addict Biol 20:469-481.

Beas BS, Wright BJ, Skirzewski M, Leng Y, Hyun JH, Koita O, Ringelberg N, Kwon HB, Buonanno A, Penzo MA (2018) The locus coeruleus drives disinhibition in the midline thalamus via a dopaminergic mechanism. Nat Neurosci 21:963-973.

Bhatnagar S, Huber R, Lazar E, Pych L, Vining C (2003) Chronic stress alters behavior in the conditioned defensive burying test: role of the posterior paraventricular thalamus. Pharmacol Biochem Behav 76:343-349.

Bird KD (2004) Analysis of variance via confidence intervals. London: Sage.

Blanchard RJ, Blanchard DC (1971) Defensive reactions in the albino rat. Learn Motiv 2:351-362.

Bland JM, Altman DG (2015) Statistics notes: bootstrap resampling methods. BMJ 350:h2622-h2622.

Browning JR, Jansen HT, Sorg BA (2014) Inactivation of the paraventricular thalamus abolishes the expression of cocaine conditioned place preference in rats. Drug Alcohol Depend 134:387-390.

Cheng J, Wang J, Ma X, Ullah R, Shen Y, Zhou YD (2018) Anterior para- 
ventricular thalamus to nucleus accumbens projection is involved in feeding behavior in a novel environment. Front Mol Neurosci 11:202.

Choi EA, McNally GP (2017) Paraventricular thalamus balances danger and reward. J Neurosci 37:3018-3029.

Colavito V, Tesoriero C, Wirtu AT, Grassi-Zucconi G, Bentivoglio M (2015) Limbic thalamus and state-dependent behavior: the paraventricular nucleus of the thalamic midline as a node in circadian timing and sleep/ wake-regulatory networks. Neurosci Biobehav Rev 54:3-17.

Corr PJ (2013) Approach and avoidance behaviour: multiple systems and their interactions. Emot Rev 5:285-290.

Corr PJ, McNaughton N (2012) Neuroscience and approach/avoidance personality traits: a two stage (valuation-motivation) approach. Neurosci Biobehav Rev 36:2339-2354.

Dickinson A, Pearce JM (1977) Inhibitory interactions between appetitive and aversive stimuli. Psychol Bull 84:690.

Do-Monte FH, Quiñones-Laracuente K, Quirk GJ (2015) A temporal shift in the circuits mediating retrieval of fear memory. Nature 519:460 - 463.

Do-Monte FH, Minier-Toribio A, Quiñones-Laracuente K, Medina-Colón EM, Quirk GJ (2017) Thalamic regulation of sucrose seeking during unexpected reward omission. Neuron 94:388-400.e4.

Dong X, Li S, Kirouac GJ (2017) Collateralization of projections from the paraventricular nucleus of the thalamus to the nucleus accumbens, bed nucleus of the stria terminalis, and central nucleus of the amygdala. Brain Struct Funct 222:3927-3943.

Fanselow MS, Bolles RC (1979) Naloxone and shock-elicited freezing in the rat. J Comp Physiol Psychol 93:736-744.

Gibson GD, Prasad AA, Jean-Richard-dit-Bressel P, Yau JO, Millan EZ, Liu Y, Campbell EJ, Lim J, Marchant NJ, Power JM, Killcross S, Lawrence AJ, McNally GP (2018) Distinct accumbens shell output pathways promote versus prevent relapse to alcohol seeking. Neuron 98:512-520.e6.

Gomez JL, Bonaventura J, Lesniak W, Mathews WB, Sysa-Shah P, Rodriguez LA, Ellis RJ, Richie CT, Harvey BK, Dannals RF, Pomper MG, Bonci A, Michaelides M (2017) Chemogenetics revealed: DREADD occupancy and activation via converted clozapine. Science 357:503-507.

Gray J, McNaughton N (2000) The europsychology of anxiety: an enquiry into the functions of the septohippocampal system. Oxford: Oxford UP.

Haight JL, Flagel SB (2014) A potential role for the paraventricular nucleus of the thalamus in mediating individual variation in Pavlovian conditioned responses. Front Behav Neurosci 8:79.

Hamlin AS, Clemens KJ, Choi EA, McNally GP (2009) Paraventricular thalamus mediates context-induced reinstatement (renewal) of extinguished reward seeking. Eur J Neurosci 29:802-812.

Harris RJ (1994) ANOVA: an analysis of variance primer. Itasca, Illinois: F.E. Peacock.

Holmes NM, Westbrook RF (2014) Appetitive context conditioning proactively, but transiently, interferes with expression of counterconditioned context fear. Learn Mem 21:597-605.

Ito R, Lee AC (2016) The role of the hippocampus in approach-avoidance conflict decision-making: evidence from rodent and human studies. Behav Brain Res 313:345-357.

Kirouac GJ (2015) Placing the paraventricular nucleus of the thalamus within the brain circuits that control behavior. Neurosci Biobehav Rev 56:315-329.

Li S, Kirouac GJ (2008) Projections from the paraventricular nucleus of the thalamus to the forebrain, with special emphasis on the extended amygdala. J Comp Neurol 506:263-287.

Li S, Kirouac GJ (2012) Sources of inputs to the anterior and posterior as- pects of the paraventricular nucleus of the thalamus. Brain Struct Funct 217:257-273.

Li Y, Dong X, Li S, Kirouac GJ (2014) Lesions of the posterior paraventricular nucleus of the thalamus attenuate fear expression. Front Behav Neurosci 8:94.

Lovibond PF, Dickinson A (1982) Counterconditioning of appetitive and defensive CRs in rabbits. Q J Exp Psychol B 34:115-126.

MacLaren DA, Browne RW, Shaw JK, Krishnan Radhakrishnan S, Khare P, España RA, Clark SD (2016) Clozapine $N$-oxide administration produces behavioral effects in Long-Evans rats: implications for designing DREADD experiments. eNeuro 3:ENEURO.0219-16.2016.

Mahler SV, Vazey EM, Beckley JT, Keistler CR, McGlinchey EM, Kaufling J, Wilson SP, Deisseroth K, Woodward JJ, Aston-Jones G (2014) Designer receptors show role for ventral pallidum input to ventral tegmental area in cocaine seeking. Nat Neurosci 17:577-585.

Miller NE (1944) Experimental studies of conflict. In: Personality and behavior disorders (Hunt JM, ed), pp 431-465. New York: Ronald.

Miller NE (1959) Liberalization of basic SR concepts: extensions to conflict behavior, motivation and social learning. In: Psychology: a study of a science (Koch S, ed), pp 196-292. New York: McGraw-Hill.

Nasser HM, McNally GP (2012) Appetitive-aversive interactions in Pavlovian fear conditioning. Behav Neurosci 126:404-422.

Nasser HM, McNally GP (2013) Neural correlates of appetitive-aversive interactions in Pavlovian fear conditioning. Learn Mem 20:220-228.

O’Neil EB, Newsome RN, Li IH, Thavabalasingam S, Ito R, Lee AC (2015) Examining the role of the human hippocampus in approach-avoidance decision making using a novel conflict paradigm and multivariate functional magnetic resonance imaging. J Neurosci 35:15039-15049.

Ong ZY, Liu JJ, Pang ZP, Grill HJ (2017) Paraventricular thalamic control of food intake and reward: role of glucagon-like peptide-1 receptor signaling. Neuropsychopharmacology 42:2387-2397.

Otis JM, Namboodiri VM, Matan AM, Voets ES, Mohorn EP, Kosyk O, McHenry JA, Robinson JE, Resendez SL, Rossi MA, Stuber GD (2017) Prefrontal cortex output circuits guide reward seeking through divergent cue encoding. Nature 543:103-107.

Paxinos G, Watson C (2007) The rat brain in stereotaxic coordinates, Ed 6. London; Amsterdam: Elsevier

Penzo MA, Robert V, Tucciarone J, De Bundel D, Wang M, Van Aelst L, Darvas M, Parada LF, Palmiter RD, He M, Huang ZJ, Li B (2015) The paraventricular thalamus controls a central amygdala fear circuit. Nature 519:455-459.

Perez SM, Lodge DJ (2018) Convergent inputs from the hippocampus and thalamus to the nucleus accumbens regulate dopamine neuron activity. J Neurosci 38:10607-10618.

Sengupta A, Winters B, Bagley EE, McNally GP (2016) Disrupted prediction error links excessive amygdala activation to excessive fear. J Neurosci 36:385-395.

Smith KS, Bucci DJ, Luikart BW, Mahler SV (2016) DREADDS: use and application in behavioral neuroscience. Behav Neurosci 130:137-155.

Vertes RP, Linley SB, Hoover WB (2015) Limbic circuitry of the midline thalamus. Neurosci Biobehav Rev 54:89-107.

Yau JO, McNally GP (2015) Pharmacogenetic excitation of dorsomedial prefrontal cortex restores fear prediction error. J Neurosci 35:74-83.

Zhu Y, Nachtrab G, Keyes PC, Allen WE, Luo L, Chen X (2018) Dynamic salience processing in paraventricular thalamus gates associative learning. Science 362:423-429. 